This is a non-peer reviewed pre-print submitted to EarthArXiV. This manuscript is currently under review at the journal Nature.

Subsequent versions of this manuscript may have slightly different content.

We welcome feedback. Please contact Matt Osman (mattosman@arizona.edu) regarding this manuscript's content. 


\section{Globally resolved surface temperatures since the Last Glacial Maximum}

Matthew B. Osman ${ }^{1 *}$, Jessica E. Tierney ${ }^{1}$, Jiang Zhu ${ }^{2}$, Robert Tardif ${ }^{3}$, Gregory J. Hakim ${ }^{3}$, Jonathan King $^{1}$, Christopher J. Poulsen ${ }^{4}$

${ }^{1}$ Department of Geosciences, The University of Arizona, Tucson, AZ 85721, USA

${ }^{2}$ Climate and Global Dynamics Laboratory, National Center for Atmospheric Research, Boulder, CO 80305, USA

${ }^{3}$ Department of Atmospheric Sciences, University of Washington, Seattle, WA 98195, USA

${ }^{4}$ Department of Earth and Environmental Sciences, University of Michigan, Ann Arbor, MI 48109, USA

*To whom correspondence should be addressed: mattosman@ arizona.edu.

Climate changes across the last 24,000 years provide key insights into Earth system responses to external forcing. Climate model simulations ${ }^{1,2}$ and proxy data ${ }^{3-8}$ have independently allowed for study of this crucial interval; however, they have at times yielded disparate conclusions. Here, we leverage both types of information using paleoclimate data assimilation 9,10 to produce the first observationally constrained, full-field reanalysis of surface temperature change spanning the Last Glacial Maximum to present. We demonstrate that temperature variability across the last $24 \mathrm{kyr}$ was linked to two modes: radiative forcing from ice sheets and greenhouse gases; and a superposition of changes in thermohaline circulation and seasonal insolation. In contrast with previous proxy-based reconstructions ${ }^{6,7}$ our reanalysis results show that global mean temperatures warmed between the early and middle Holocene and were stable thereafter. When compared with recent temperature changes ${ }^{11}$, our reanalysis indicates that both the rate and magnitude of modern observed warming are unprecedented relative to the changes of the last $24 \mathrm{kyr}$. 
The interval of time spanning the Last Glacial Maximum (LGM; 21-18 ka) to the preindustrial era represents the most recent large-scale reorganization of the climate system, during which the Earth rapidly transitioned out of a cold, glaciated state with vast Northern Hemisphere ice sheets into a warm interglacial. Constraining the evolution of global surface temperatures during this critical time period provides an excellent opportunity to better understand the mechanisms of largescale climate change, including Earth system interactions and responses to various forcings (e.g., greenhouse gases, albedo/ice-sheet, and orbital changes).

A number of prior studies have attempted to characterize the global surface temperature evolution from the LGM to present ${ }^{3-7}$. Of particular note, Shakun et al. ${ }^{3}$ and Marcott et al. ${ }^{6}$ established a global mean surface temperature (GMST) estimate spanning the deglacial and Holocene periods using a limited $(n \leq 80)$, globally dispersed marine and terrestrial temperature proxy database (hereafter, the Shakun-Marcott Curve; SMC). However, subsequent comparisons of SMC to both independent temperature reconstructions and transient LGM-to-present model simulations, such as TraCE-21k ${ }^{1,12}$, revealed discrepancies surrounding the abruptness, magnitude, and rapidity of deglacial global warming ${ }^{2,4,12}$, as well as the phasing and magnitude of millennial-scale deglacial cooling events ${ }^{1,13,14}$. One of the most prominent differences between SMC and climate model simulations is the direction of global temperature change across the Holocene. Whereas SMC shows a cooling trend, modeling results indicate there should be a warming, a phenomenon termed the "Holocene Temperature Conundrum" ${ }^{2}$. More recent work has sought to reconcile these differences by using either independent ${ }^{5,15}$ or additional ${ }^{7,15}$ proxies, and by correcting for possible proxy seasonal biases ${ }^{2,8,15}$. Nonetheless, all of these approaches have a fundamental limitation in that none provide a dynamically consistent full-field view of climate evolution since the LGM. Conversely, although climate models provide a self-consistent and spatially complete representation of the climate system, they are known to have biases due to inaccurate representation of climate processes. Additionally, the fidelity of paleoclimate simulations of the LGM and Holocene depends on the accurate knowledge of paleoclimate boundary conditions, which are known with 
varying levels of certainty $2,16,17$.

\section{The Last Glacial Maximum Reanalysis}

Here, we revisit the evolution of global temperatures from the LGM to present using an offline paleoclimate data assimilation approach that formally combines proxy and model information $9,10,18$. The resulting "Last Glacial Maximum Reanalysis" (LGMR) product offers a complete spatiotemporal view of climate change for the last $24 \mathrm{kyr}$. The LGMR enables us to diagnose the major modes of climate variability, refine our understanding of global temperature changes across the Holocene, and compare the current anthropogenic global warming with the rate and magnitude of change seen in the recent geological record.

Following ref. ${ }^{10}$, we focus on assimilating geochemical proxies for sea-surface temperature (SST) with established Bayesian forward models ${ }^{19-22}$. To ensure that the proxy data had sufficient temporal resolution and length to inform our reconstruction, we required that records be at least 4,000 years long, have a median time resolution of 1,000 years or less, and contain a radiocarbonbased age model. The temporal criteria were relaxed for sites in the Southern Ocean to increase coverage in this data-poor region. Conversely, some SST records that met these criteria were excluded due to complications related to proxy interpretation and (or) their location (see Methods). In total, our vetted compilation consists of 539 records, including 133 alkenone $\left(U_{37}^{K^{\prime}}\right), 25$ TetraEther indeX of 86 carbons $\left(\mathrm{TEX}_{86}\right), 123$ planktic foraminiferal $\mathrm{Mg} / \mathrm{Ca}$, and 258 planktic foraminiferal oxygen isotope $\left(\delta^{18} \mathrm{O}_{c}\right)$ time series (Fig. 1 and Extended Data Figure 1).

Our proxy compilation provides unprecedented insight into LGM-to-present climate evolution on its own, but transient offline data assimilation further leverages the full-field dynamical insights available from climate model simulations and bypasses issues related to heterogeneous proxy spatial distribution ${ }^{3,4,6-8}$. The model simulations used for the assimilation consist of 17 LGM-to-present time-slice experiments conducted with the isotope-enabled Community Earth System Model version 1 (iCESM1; Extended Data Table 1 and Methods; ${ }^{10,23}$ ). We draw an 
ensemble of 50-yr average states from these simulations for our model "prior". The model prior includes all of the variables needed by our proxy forward models (monthly salinity and SST, and mean-annual $\delta^{18} \mathrm{O}$ of seawater; Methods) as well as other variables of climatic interest including mean annual surface air temperature (SAT) and the $\delta^{18} \mathrm{O}$ of precipitation $\left(\delta^{18} \mathrm{O}_{p}\right)$. We reconstruct climate at 200-year intervals, adhering to the resolution limitations of the majority ( $>90 \%$ ) of our proxy data. For a given time interval, we estimate proxy values from the model prior at the locations where geochemical measurements exist using Bayesian forward models (Methods). The difference between the actual proxy value and the forward modeled value (the "innovation") is first weighted by the Kalman gain-which considers the covariance between the proxy location and the climate fields as well as uncertainties in the proxies and the prior-and is then added to the model prior state. For our final reconstruction, we produced a posterior ensemble of 300 realizations, based on sampling 60 representative prior iCESM states for each time interval (Methods), with $20 \%$ of proxy records randomly withheld for error quantification and validation testing. For each ensemble member, we also sampled age uncertainty to ensure that this source of error was propagated into our assimilated fields (Methods).

The LGMR highlights the exceptional and spatially heterogeneous nature of deglacial climate change (Fig. 2). Reconstructed global mean surface temperature (GMST) reveals a significant ( $p<0.05$; Methods) three-part sequence across the last 24 ka. From 24-17 kyr BP, the Earth is in a ubiquitously cold glacial state. The thermal imprints of the North American and Eurasian ice sheets are near their maximum extent, with terrestrial cooling relative to the pre-industrial in excess of $-20^{\circ} \mathrm{C}$ across the glaciated high northern $\left(>45^{\circ} \mathrm{N}\right)$ and southern $\left(>45^{\circ} \mathrm{S}\right)$ latitudes (Fig. 2). At $17.2 \mathrm{ka}(95 \% \mathrm{CI}=18.7-16.4 \mathrm{ka}$, Methods), global-scale deglaciation (the second stage) abruptly begins. Deglacial global warming shows a familiar ${ }^{3}$ two-step rise that is punctuated by the millennial-scale Bølling-Allerød (14.8-12.8 ka) to Younger Dryas (12.8-11.7 ka) events. Following the Younger Dryas cold spell, the Earth enters its final transition towards the present interglacial. In the third part of the GMST sequence, gradual early Holocene (11 kyr BP onward) 
warming stabilizes to near pre-industrial temperatures (i.e., within $\left.\sim 0.5^{\circ} \mathrm{C}\right)$ by $9.2 \mathrm{ka}(95 \% \mathrm{CI}=$ 11.0-8.3 ka). A vestigial cold imprint atop northeastern North America is all that remains of the once-great Northern Hemisphere ice sheets as mild, albeit widespread, high-latitude warming ensues; Antarctica now shows a notable east-west thermal dipole next to a relatively warm Southern Ocean, whereas mild cooling persists across much of the tropics (Fig. 2). All told, we estimate a mean global warming of $6.8 \pm 0.8{ }^{\circ} \mathrm{C}(2 \sigma)$ from the deglaciation onset at $17.2 \mathrm{ka}$ to pre-industrial, broadly in line with, though slightly larger than, the value reported in ref. ${ }^{10}\left(6.1^{\circ} \mathrm{C}\right)$. The greater warming found here reflects the LGM period referenced (ref. ${ }^{10}$ uses $23-19 \mathrm{kyr}$, which includes mildly warmer GMST according to the LGMR) as well as differences in iCESM model priors and proxy data distribution (Methods).

\section{Validating the LGMR}

We objectively test the skill of the LGMR using two independent methods of statistical validation. First, we use our posterior LGMR fields to reconstruct the randomly withheld proxy time series (e.g., ref. ${ }^{18}$ ). Across the ensemble, we find that the majority of records are skillfully reconstructed with no obvious signs of regional bias, suggesting that our posterior assimilation is robust (Extended Data Figure 2; Methods). Second, following ref. ${ }^{10}$, we compare posterior $\delta^{18} \mathrm{O}_{p}$ to independent ice core- and speleothem-derived $\delta^{18} \mathrm{O}$ time series (Extended Data Table 2). On a global scale, we find notable improvement in the posterior comparison of $\Delta \delta^{18} \mathrm{O}_{p}$ over the prior state, with a $\sim 30 \%$ reduction of bias and a large increase in variance explained (Extended Data Figure 3). In particular, the millennial-scale correspondence of the ice core records with LGMR $\delta^{18} \mathrm{O}_{p}$ is remarkable, with $\mathrm{R}^{2}$ values ranging from 0.65 to $0.90(n=14$ records; Extended Data Table 2, Extended Data Figure 4). 


\section{Drivers of global SAT change}

To gain further insight into the drivers of global surface temperature change during the last 24 ka, we decompose our LGMR temperature fields into spatiotemporal modes of variability using Empirical Orthogonal Function (EOF) analysis, following past studies that relied solely on proxies 24,25. As expected, the first spatial mode, EOF1, exhibits positive loading across the globe and explains the overwhelming majority ( $>90 \%$ ) of the surface temperature covariance during the last 24 ka (Fig. 3a). This mode is clearly associated with deglaciation, with the strongest amplitude concentrated atop the North American and Fennoscandian ice sheets. The unimodal nature of EOF1 implies an association with changes in greenhouse gas (GHG) radiative forcing and ice sheet albedo. Given the monotonic nature of the associated principal component time series, PC1, GHG forcing ${ }^{26}$ can explain 93\% of the EOF1 variance (Fig. 3b). However, there are notable differences in the two time series; during the early- to mid-Holocene, GHG radiative forcing increases at ca. $12 \mathrm{ka}$ and then gradually decreases, while PC1 steadily increases, indicating a steady increase in global temperature. This implies GHG forcing alone is not sufficient for explaining the leading mode of global temperature variability.

Modeling experiments indicate that the magnitude of ice sheet albedo forcing is comparable to (if not greater than) GHG forcing across the deglacial transition ${ }^{10,27,28}$. By considering GHG and ice sheet forcing together, we account for $>99 \%$ of the variance in $\mathrm{PC} 1$ as well as the observed warming from the early to mid-Holocene (Fig. 3c). The inclusion of ice sheet albedo forcing also explains the strong EOF1 loading atop North America and Fennoscandia (Fig. 3a). While we acknowledge that other radiative forcings, such as vegetation and dust, likely impacted LGM-topresent temperature change ${ }^{10}$ our EOF results imply that these were probably of second-order importance in terms of their climatic footprint, particularly during deglaciation.

The second mode of global temperature variability, EOF2, explains only 3\% of the variance. However, it is distinct from its neighboring tailing modes ${ }^{29}$ and physically interpretable. 
This mode is a hemispheric dipole, with strong positive loading across the Southern Hemisphere (especially in the Southern Ocean) and negative loading spanning much of the Northern Pacific, North America, and the North Atlantic. Its associated time series, PC2, consists of both long-term trends as well as millennial-scale peaks during the deglaciation. We interpret this mode to represent a superposition of two sources of climate variability: thermohaline circulation changes (the millennial-scale features) and shifts in high-latitude seasonal insolation (the long-term trends). To illustrate this, we decompose PC2 into its "trend" (Fig. 3c, purple) and "residual" (Fig. 3c, yellow).

The trend-component of PC2 represents a precession cycle, with a peak at ca. $11 \mathrm{ka}$. Both summer insolation intensity at $65^{\circ} \mathrm{N}^{30}$ and Southern Hemisphere summer duration at $65^{\circ} \mathrm{S}^{31}$ offer good approximations of this long-term change (Fig. 3c). The spatial pattern of EOF2, however, which shows positive loading in the Southern Ocean and negative loading in the Northern Hemisphere (Fig. 3b), suggests that Southern Hemisphere summer duration is the likely driver. It is unclear how enhanced summer insolation in the Northern Hemisphere would lead to mean annual cooling, given that this conflicts with conventional Milankovitch orbital theory ${ }^{32}$ ). In addition, spatial correlation analyses (of either orbital series) with surface temperatures indicate that the tightest coupling occurs in the Southern Hemisphere (Extended Data Figure 5b). The strong loading of EOF2 in the Southern Ocean in particular could point towards a feedback with regional sea ice; a longer summer (and shorter winter) would increase the extent of summertime sea ice retreat while decreasing its growth during wintertime, resulting in an increase in mean annual surface temperatures ${ }^{31}$.

The residual-component of PC2 closely follows $\left(\mathrm{R}^{2}=0.80\right){ }^{231} \mathrm{~Pa} /{ }^{230} \mathrm{Th}$ proxy records of Atlantic Meridional Overturning circulation (AMOC) from the Bermuda Rise ${ }^{33-35}$ (Fig. 3c). Prior studies have also identified this "bipolar seesaw" mode ${ }^{24,25}$, which represents the millennialscale events that occur during the last deglaciation (Heinrich event 1, the Bølling-Allerød, and the Younger Dryas). Correlation analysis shows that Northern Hemisphere surface temperatures in 
LGMR are strongly related to AMOC changes (Extended Data Figure 5c). A decrease in Atlantic heat transport would also lead to compensating warmth in the Southern Hemisphere, similar to what we observe in the loading pattern of EOF2. However, the particularly strong loading we observe across the Indian and Pacific ocean sectors of the Southern Ocean does not match the classic fingerprint of the oceanic bipolar seesaw ${ }^{36}$. Similarly, the strong loading in the eastern North Pacific is not typical of a modeled response to an AMOC slowdown ${ }^{1,12,37}$. It does, however, reflect the underlying proxy records from this region, which show a strong response of SST to North Atlantic climate variability ${ }^{38}$. It also conforms to recent suggestions that Columbia River megaflood meltwater forcing might have contributed to the severe cooling observed in deglacial SST records from the Gulf of Alaska ${ }^{13}$.

\section{Comparison to proxy-only insights}

LGMR GMST shows several notable differences when compared to the proxy-only SMC reconstruction (Fig. 4a). Focusing first on pre-Holocene differences, the LGMR has 1) a more abrupt onset of deglaciation at $\sim 17.2 \mathrm{ka} ; 2$ ) a more muted Bølling-Allerød-Younger Dryas transition; and 3) nearly twice as much glacial cooling (Fig. 4). The latter difference can be explained by the fact that the SMC is mostly based on SST proxies and was not scaled to infer GMST (i.e., ref. ${ }^{4}$ ). To diagnose the origin of the other differences, we generated a proxy-only GMST reconstruction from our SST compilation (Methods). Even though our compilation has many more proxy SST records than SMC (and no terrestrial records), it is remarkably similar $\left(\mathrm{R}^{2}=0.97\right.$; Fig. 4a).

The similarity of the proxy-only reconstruction and the SMC illuminates at least two shortcomings that are effectively mitigated by our data assimilation approach. Proxy-specific GMST reconstructions (Extended Data Figure 6) suggest that the gradual deglacial onset is most likely linked to the $\mathrm{Mg} / \mathrm{Ca}$ data, which show early deglacial SST increases and a sustained warm bias relative to $\delta^{18} \mathrm{O}_{c}$ and (to a lesser extent) $U_{37}^{K^{\prime}}$ (Extended Data Figure 6). Data assimilation will down-weight these differences if they occur in the presence of more internally consistent signals 
from other proxies. Second, data assimilation allows us to overcome problems associated with spatial bias in the proxy distribution (c.f., Fig. 1). Unlike the enhanced Younger Dryas cooling shown by the proxy only curves (Fig. 4), LGMR reveals that Younger Dryas cooling was in fact confined to the Northern Hemisphere (and, specifically, the North Atlantic and North Pacific sectors; Extended Data Figure 7). The stronger expression of the YD in the proxy-only GMST curves likely reflects the Northern Hemisphere bias in the underlying proxy distribution (Fig. 1a).

\section{Holocene global temperature trends}

The LGMR provides an updated view of the "Holocene Temperature Conundrum" ${ }^{2}$. All of the proxy-only reconstructions-including SMC, Temp $12 \mathrm{~K}^{7}$, and ours-show a cooling trend that begins at $\sim 9.5-6.5 \mathrm{kyr}$ BP and continues through the rest of the Holocene (Fig. 4b) which, as shown previously ${ }^{2,8,15}$, disagrees with TraCE-21k (Fig. 4b). In contrast, LGMR shows that GMST was relatively stable from $\sim 8 \mathrm{kyr} \mathrm{BP}$ to pre-industrial, and remains within $<0.5^{\circ} \mathrm{C}$ of $\mathrm{TraCE}-21 \mathrm{k}$ GMST anomalies for $>90 \%$ of the Holocene (Fig. 4b). The "flat" Holocene trend in LGMR does not come directly from the model prior; the $6 \mathrm{ka}$ model simulations in particular are warmer than the posterior solution (c.f., Extended Data Table 2 and Methods). Rather, it is a feature of the assimilation. Disagreement between proxy types, including the early Holocene warming in $\mathrm{Mg} / \mathrm{Ca}$ and $U_{37}^{K^{\prime}}$ that underlies the Conundrum, is nearly eliminated after assimilating each into iCESM (Extended Data Figure 6). Such consistency implies that a cold early Holocene and stable midlate Holocene is the most dynamically consistent and robust solution. Notably, this solution is not exactly the same as the temperature evolution in TraCE-21k (Fig. 4b). LGMR indicates warmer GMST from 9-5 kyr, reflecting warming in the high northern latitudes and the Southern Ocean (Fig. 2). This suggests either seasonal rectification processes taking place in the climate system that are underrepresented in models ${ }^{2,16,17}$, or other deficiencies in TraCE-21k.

Recently, Bova et al. ${ }^{8}$ suggested that proxy-based Holocene cooling ${ }^{6,7}$ reflects orbitally induced seasonal biases. Using a detrended compilation of $\mathrm{Mg} / \mathrm{Ca}$ and $U_{37}^{K^{\prime}}$ records, these authors 
produced a SST reconstruction between $40^{\circ} \mathrm{S}$ and $40^{\circ} \mathrm{N}$ that shows a steady Holocene SST warming of ca. $0.5^{\circ} \mathrm{C}$ during the last $10 \mathrm{ka}$. Average LGMR SSTs from $40^{\circ} \mathrm{S}$ and $40^{\circ} \mathrm{N}$ are very similar (Fig. 4b); however, we did not detrend any data. Rather, we use proxy forward models that account for seasonal growth where this is expected on a first-principles basis ${ }^{20-22}$, which effectively mitigates the influence of seasonal bias on Holocene temperature evolution. However, LGMR further shows that Holocene warming is in fact subdued once the high latitudes-which are warmer in the early and mid-Holocene- are taken into account (Figs. 2-3). When global land areas are further considered, the Holocene temperature trajectory is nearly flat (Fig. 4). This highlights the importance of considering the full global land and ocean area when inferring global trends-a clear strength of the LGMR over existing proxy-only methods.

Finally, the LGMR allows us to directly assess 20th and 21st century warming from the broader vantage point of the past $24 \mathrm{ka}$. When juxtaposed alongside the Last Millennium Reanalysis version 2.1 (also a paleoclimate data assimilation product; ${ }^{18}$ ) and observational HadCRUT5 ${ }^{11}$ GMST (Fig. 2), we find that 2010-2019 mean GMST exceeds the upper bound (99th percentile) of decadal-estimated values from the LGMR by a considerable margin $->0.5^{\circ} \mathrm{C}$, or $+1.4^{\circ} \mathrm{C}$ above mean Holocene GMST. These findings contradict those of Marcott et al. ${ }^{6}$, who suggested that early 21 st century temperatures (2000-2009) had not yet exceeded early Holocene values and reflect increased confidence over ref. ${ }^{7}$, who find that 2010-2019 warming is at the $\sim 80 \%$ of mid-Holocene centennial-scale values. Similarly, we find the HadCRUT5-observed rate of 20th to 21st century warming $\left(0.96^{\circ} \mathrm{C}\right.$ per century) registers near the upper bound of LGMR deglacial warming rates (i.e., $>99.9$ th percentile, Extended Data Figure 8 and Methods). As such, the LGMR underscores the dramatic nature of anthropogenic warming, whose magnitude and rate appears unprecedented in the context of the last $24 \mathrm{ka}$. 


\section{References}

1. Liu, Z. et al. Transient Simulation of Last Deglaciation with a New Mechanism for BøllingAllerød Warming. Science 325, 310 LP - 314 (2009).

2. Liu, Z. et al. The Holocene temperature conundrum. Proceedings of the National Academy of Sciences 111, E3501 LP - E3505 (2014).

3. Shakun, J. D. et al. Global warming preceded by increasing carbon dioxide concentrations during the last deglaciation. Nature 484, 49-54 (2012).

4. Snyder, C. W. Evolution of global temperature over the past two million years. Nature 538, 226-228 (2016).

5. Bereiter, B., Shackleton, S., Baggenstos, D., Kawamura, K. \& Severinghaus, J. Mean global ocean temperatures during the last glacial transition. Nature 553, 39-44 (2018).

6. Marcott, S. A., Shakun, J. D., Clark, P. U. \& Mix, A. C. A Reconstruction of Regional and Global Temperature for the Past 11,300 Years. Science 339, 1198 LP - 1201 (2013).

7. Kaufman, D. et al. Holocene global mean surface temperature, a multi-method reconstruction approach. Scientific Data 7, 201 (2020).

8. Bova, S., Rosenthal, Y., Liu, Z., Godad, S. P. \& Yan, M. Seasonal origin of the thermal maxima at the Holocene and the last interglacial. Nature 589, 548-553 (2021).

9. Hakim, G. J. et al. The last millennium climate reanalysis project: Framework and first results. Journal of Geophysical Research: Atmospheres 121, 6745-6764 (2016).

10. Tierney, J. E. et al. Glacial cooling and climate sensitivity revisited. Nature 584, 569-573 (2020). 
11. Morice, C. P. et al. An updated assessment of near-surface temperature change from 1850: the HadCRUT5 dataset. Journal of Geophysical Research: Atmospheres 126, e2019JD032361 (2020).

12. He, F. et al. Northern Hemisphere forcing of Southern Hemisphere climate during the last deglaciation. Nature 494, 81-85 (2013).

13. Praetorius, S. K. et al. The role of Northeast Pacific meltwater events in deglacial climate change. Science Advances 6, eaay2915 (2020).

14. Walczak, M. H. et al. Phasing of millennial-scale climate variability in the Pacific and Atlantic Oceans. Science 370, 716 LP - 720 (2020).

15. Marsicek, J., Shuman, B. N., Bartlein, P. J., Shafer, S. L. \& Brewer, S. Reconciling divergent trends and millennial variations in Holocene temperatures. Nature 554, 92-96 (2018).

16. Brierley, C. M. et al. Large-scale features and evaluation of the PMIP4-CMIP6 mid-Holocene simulations. Climate of the Past 16, 1847-1872 (2020).

17. Park, H.-S., Kim, S.-J., Stewart, A. L., Son, S.-W. \& Seo, K.-H. Mid-Holocene Northern Hemisphere warming driven by Arctic amplification. Science Advances 5, eaax8203 (2019).

18. Tardif, R. et al. Last Millennium Reanalysis with an expanded proxy database and seasonal proxy modeling. Clim. Past 15, 1251-1273 (2019).

19. Tierney, J. E. \& Tingley, M. P. A Bayesian, spatially-varying calibration model for the TEX86 proxy. Geochimica et Cosmochimica Acta 127, 83-106 (2014).

20. Tierney, J. E. \& Tingley, M. P. BAYSPLINE: A New Calibration for the Alkenone Paleothermometer. Paleoceanography and Paleoclimatology 33, 281-301 (2018). 
21. Malevich, S. B., Vetter, L. \& Tierney, J. E. Global Core Top Calibration of $\delta 180$ in Planktic Foraminifera to Sea Surface Temperature. Paleoceanography and Paleoclimatology 34, 12921315 (2019).

22. Tierney, J. E., Malevich, S. B., Gray, W., Vetter, L. \& Thirumalai, K. Bayesian Calibration of the $\mathrm{Mg} / \mathrm{Ca}$ Paleothermometer in Planktic Foraminifera. Paleoceanography and Paleoclimatology 34, 2005-2030 (2019).

23. Brady, E. et al. The Connected Isotopic Water Cycle in the Community Earth System Model Version 1. Journal of Advances in Modeling Earth Systems 11, 2547-2566 (2019).

24. Clark, P. U. et al. Global climate evolution during the last deglaciation. Proceedings of the National Academy of Sciences 109, E1134 LP - E1142 (2012).

25. Shakun, J. D. \& Carlson, A. E. A global perspective on Last Glacial Maximum to Holocene climate change. Quaternary Science Reviews 29, 1801-1816 (2010).

26. Köhler, P., Nehrbass-Ahles, C., Schmitt, J., Stocker, T. F. \& Fischer, H. A 156kyr smoothed history of the atmospheric greenhouse gases $\mathrm{CO} 2, \mathrm{CH} 4$, and $\mathrm{N} 2 \mathrm{O}$ and their radiative forcing. Earth Syst. Sci. Data 9, 363-387 (2017).

27. Braconnot, P. \& Kageyama, M. Shortwave forcing and feedbacks in Last Glacial Maximum and Mid-Holocene PMIP3 simulations. Philosophical Transactions of the Royal Society A: Mathematical, Physical and Engineering Sciences 373, 20140424 (2015).

28. Baggenstos, D. et al. Earth's radiative imbalance from the Last Glacial Maximum to the present. Proceedings of the National Academy of Sciences 116, 14881 LP - 14886 (2019).

29. North, G. R., Bell, T. L., Cahalan, R. F. \& Moeng, F. J. Sampling Errors in the Estimation of Empirical Orthogonal Functions. Monthly Weather Review 110, 699-706 (1982). 
30. Berger, A. Long-Term Variations of Daily Insolation and Quaternary Climatic Changes. Journal of Atmospheric Sciences 35, 2362-2367 (1978).

31. Huybers, P. \& Denton, G. Antarctic temperature at orbital timescales controlled by local summer duration. Nature Geoscience 1, 787-792 (2008).

32. Imbrie, J. et al. On the Structure and Origin of Major Glaciation Cycles 1. Linear Responses to Milankovitch Forcing. Paleoceanography 7, 701-738 (1992).

33. McManus, J. F., Francois, R., Gherardi, J.-M., Keigwin, L. D. \& Brown-Leger, S. Collapse and rapid resumption of Atlantic meridional circulation linked to deglacial climate changes. Nature 428, 834-837 (2004).

34. Böhm, E. et al. Strong and deep Atlantic meridional overturning circulation during the last glacial cycle. Nature 517, 73-76 (2015).

35. Lippold, J. et al. Constraining the Variability of the Atlantic Meridional Overturning Circulation During the Holocene. Geophysical Research Letters 46, 11338-11346 (2019).

36. Pedro, J. B. et al. Beyond the bipolar seesaw: Toward a process understanding of interhemispheric coupling. Quaternary Science Reviews 192, 27-46 (2018).

37. Ritz, S. P., Stocker, T. F., Grimalt, J. O., Menviel, L. \& Timmermann, A. Estimated strength of the Atlantic overturning circulation during the last deglaciation. Nature Geoscience 6, 208$212(2013)$.

38. Praetorius, S. K. et al. North Pacific deglacial hypoxic events linked to abrupt ocean warming. Nature 527, 362-366 (2015).

39. Peltier, W. R., Argus, D. F. \& Drummond, R. Space geodesy constrains ice age terminal deglaciation: The global ICE-6G_C (VM5a) model. Journal of Geophysical Research: Solid Earth 120, 450-487 (2015). 


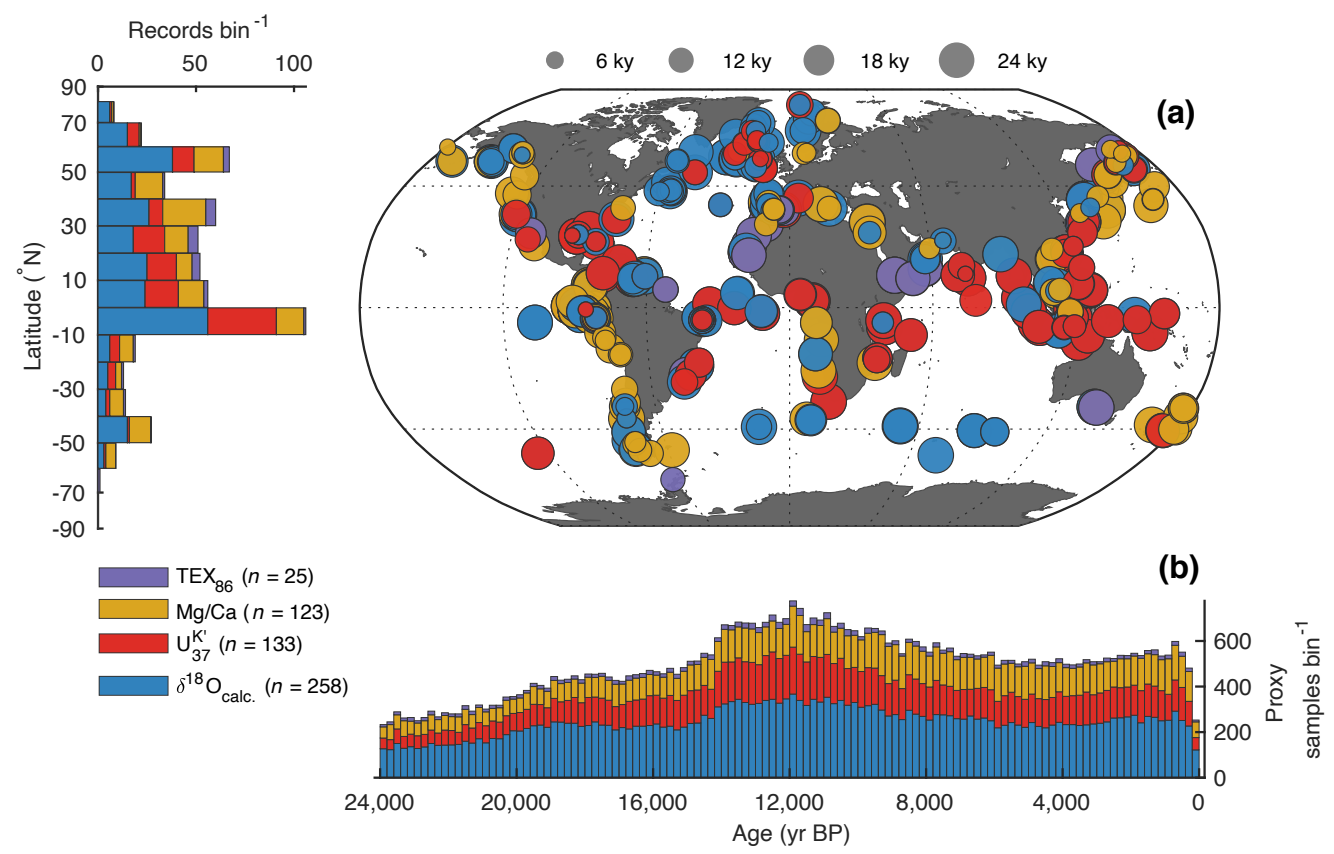

Fig. 1. Locations and temporal coverage of the SST proxies. (a) Site locations of $\mathrm{TEX}_{86}, \mathrm{Mg} / \mathrm{Ca}, U_{37}^{K^{\prime}}$ and $\delta^{18} \mathrm{O}_{\text {calc. }}$ records (right), as well as their latitudinal distribution (left). (b) Temporal coverage of the proxies, binned at $200 \mathrm{yr}$ intervals. 


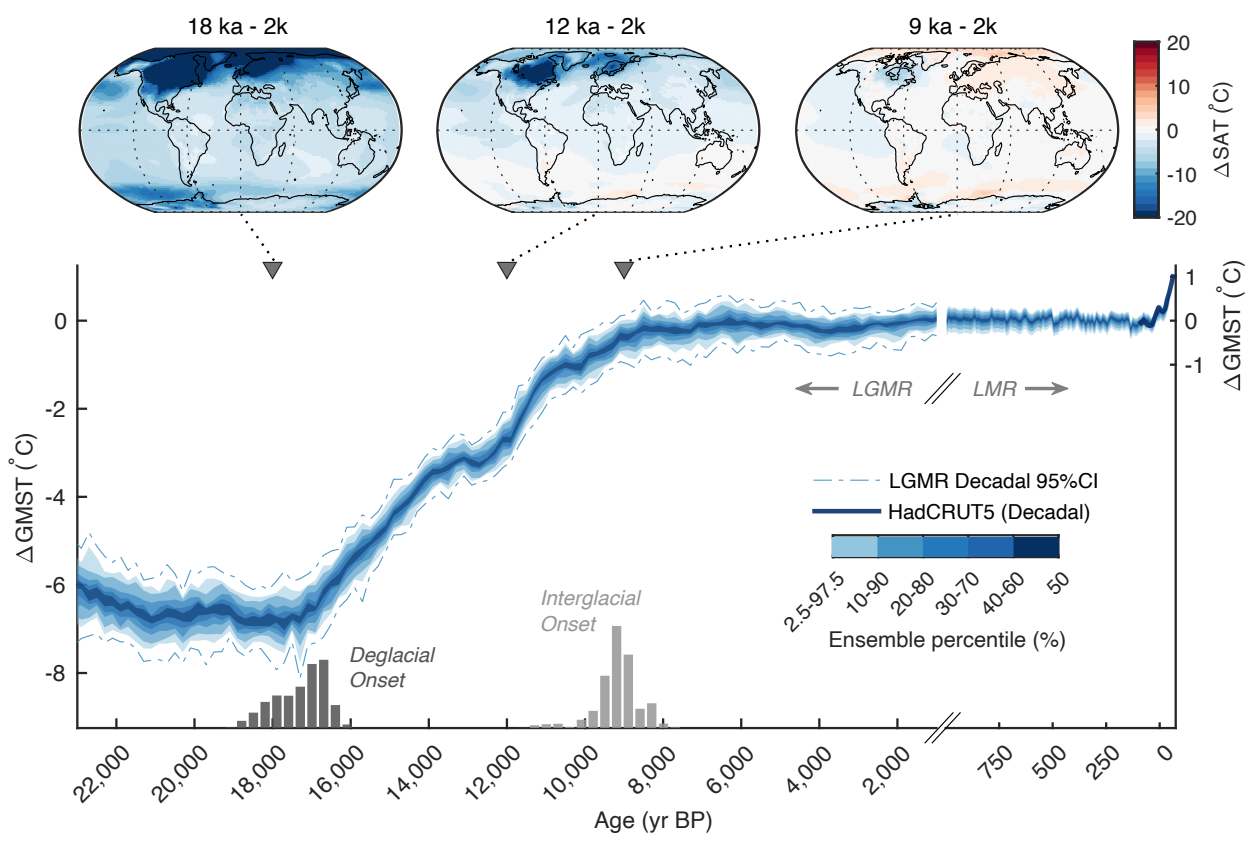

Fig. 2. Global mean surface temperature change over the last 24 ka. Ensemble distribution $(n=300)$ of LGMR GMST for the past $24 \mathrm{ka}$ (blue colors), with a decadal $95^{\text {th }}$-percentile range (dotted-dashed lines) estimated using time-evolving GMST decadal-to-centennial mean ratios from iCESM (Methods). Shown at top are corresponding spatial surface temperature anomalies for intervals discussed in the main text. The estimated last deglacial and interglacial onset timings are shown as dark and light histograms at bottom (Methods). Juxtaposed alongside the LGMR (right-hand side) are reconstructed decadal GMST's from the Last Millennium Reanalysis v2. $1^{18}$ and HadCRUT5 observational product ${ }^{11}$. $\Delta$ GMST is computed relative to the pre-industrial last millennium average (1000-1850 CE). 

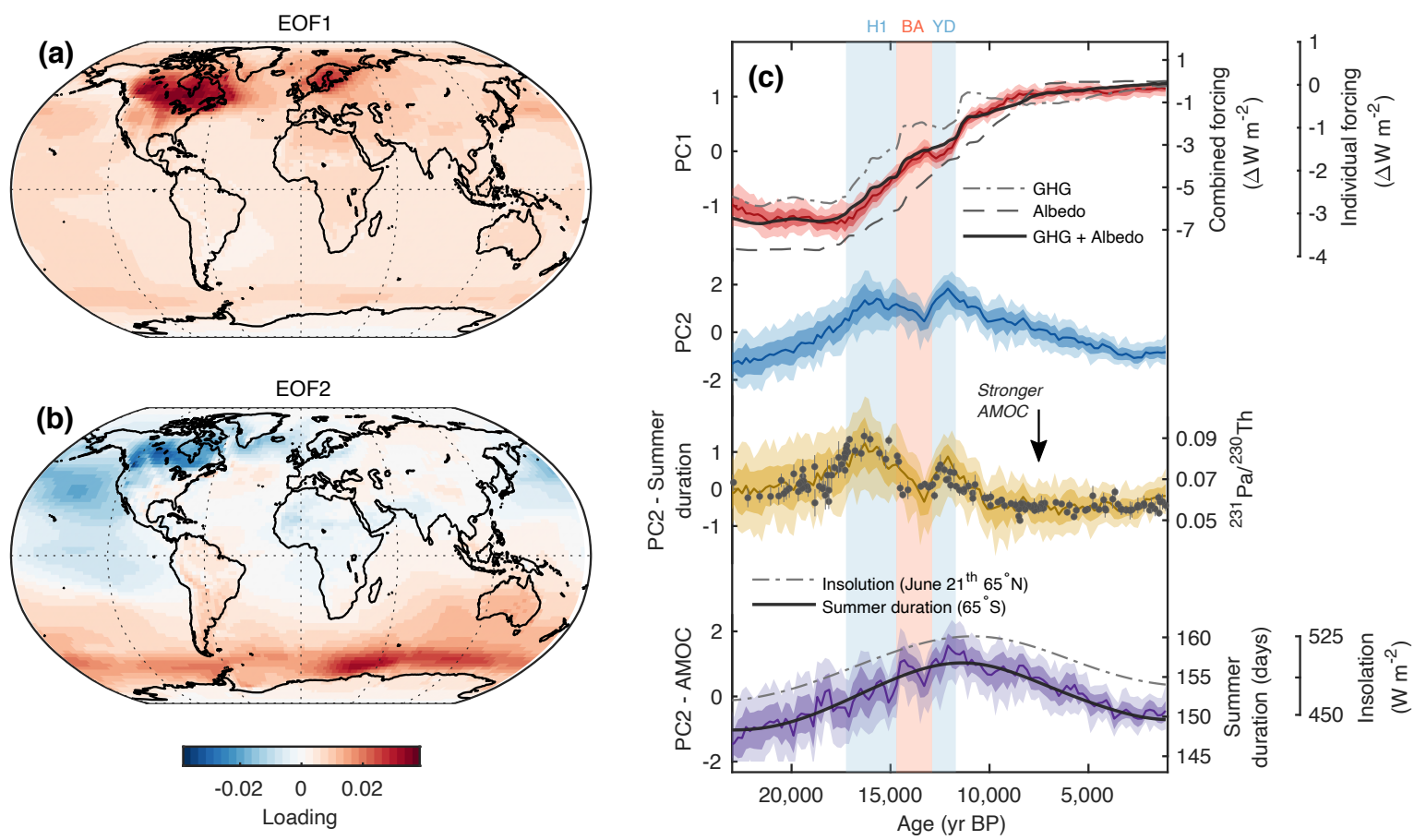

Fig. 3. Leading modes of LGM-to-present surface temperature variability. (a-b) Empirical orthogonal function (EOF) 1 and EOF2 of SAT during the last $24 \mathrm{ka}$. (c) Comparison between the associated principal component time series and climatic drivers. From top: PC1 (red) vs. greenhouse gas (GHG) radiative forcing ${ }^{26}$, albedo radiative forcing (derived by scaling changes in ICE-6G-estimated global ice sheet area 39 to multi-model LGM global albedo forcing following ref. ${ }^{28}$ ), and combined GHG and albedo radiative forcing; PC2 (blue); the residual of the regression of $65^{\circ} \mathrm{S}$ summer-duration onto PC2 (gold) vs. AMOC proxies from the Bermuda Rise $\left({ }^{231} \mathrm{~Pa} /{ }^{230} \mathrm{Th}\right.$; error bars indicate $2 \sigma$ uncertainty $\left.{ }^{35}\right)$; and the residual of the regression of AMOC proxies onto PC2 (purple) vs. summer solstice $65^{\circ} \mathrm{N}$ insolation forcing ${ }^{30}$ and $65^{\circ} \mathrm{S}$ summer-duration (the latter denoting the number of days where mean-annual insolation exceeds $250 \mathrm{~W} \mathrm{~m}^{-2}$ following ${ }^{31}$ ). All PC series are in normalized units. Dark and lighter shading on the time series indicate $1 \sigma$ and $95 \%$ confidence intervals, respectively. Heinrich 1 (H1), the Bølling-Allerød (BA), and the Younger Dryas (YD) are also indicated. 


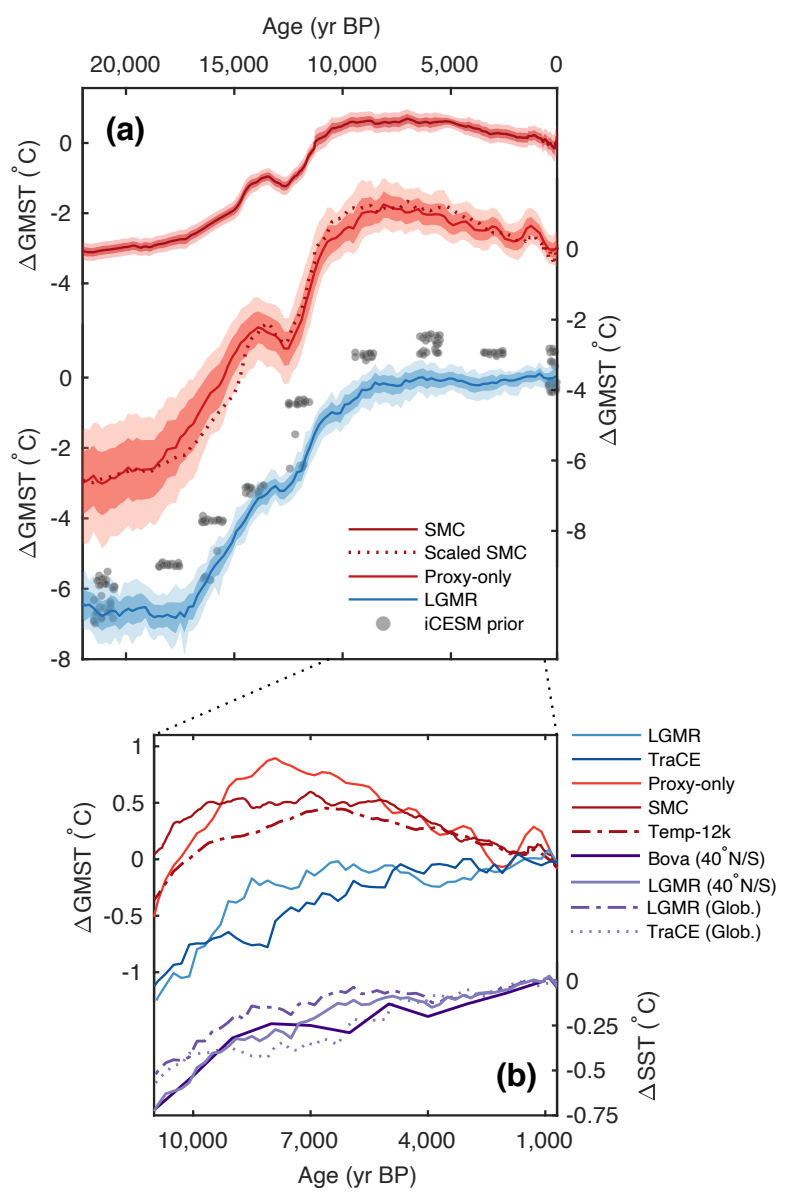

Fig. 4. Comparison of LGM-to-present surface temperature reconstructions. a) the SMC curve (dark red); proxy-only GMST (this study; light red), overlain with the GMST-scaled SMC curve (dotted dark red); and LGMR GMST (this study; blue). iCESM prior GMST values are shown in grey. Uncertainty ranges denote $\pm 1 \sigma$ (dark) and 95\% confidence intervals (light). (b) Holocene temperature trends from (a) differenced relative to the last millennium, alongside the Holocene reconstructions of ref. " ("Temp-12k"; red dotted-dashed), ref. ${ }^{8}$ ("Bova"; dark purple), and TraCE-21k predictions ${ }^{1}$. 


\section{Methods}

Proxy compilation and screening We collated a globally dispersed set of 573 sea surface temperature (SST) proxy records spanning the past 24 thousand years before present (kyr BP). Following ref. ${ }^{10}$, we focus on geochemical proxies for SST including alkenone $U_{37}^{K^{\prime}}$ (146 records), the TetraEther indeX of 86 carbons $\left(\mathrm{TEX}_{86} ; 28\right.$ records), the elemental ratio of $\mathrm{Mg}$ to $\mathrm{Ca}$ in planktic foraminifera ( $\mathrm{Mg} / \mathrm{Ca} ; 129$ records), and the oxygen isotopic composition of planktic foraminifera $\left(\delta^{18} \mathrm{O}_{c} ; 270\right.$ records $)$. As in ref. ${ }^{10}$, we limit our analyses to these proxies because we have already developed Bayesian forward models for each of them ${ }^{19-22}$ that we can use in our paleoclimate data assimilation scheme (see "Paleoclimate data assimilation", below). For consistency, we recalibrated all age models using the Marine13 radiocarbon calibration curve ${ }^{40}$ with the BACON age model program ${ }^{41}$. This procedure also allowed us to generate ensembles $(n=1,000)$ of possible age models for each record that were used to propagate dating uncertainties into our data assimilation product (c.f. sections "Paleoclimate data assimilation" and "Proxy-only global mean temperature" below).

Some screening of our proxy compilation was necessary to remove low resolution, short, and adversely situated proxy records. Generally speaking, we removed records whose median age resolution was less than 1,000 years and (or) were less than 4,000 years long (Extended Data Figure 1). However, this constraint was relaxed for records situated in or near the Southern Ocean, where data coverage is sparse, so as to retain as many time series as possible from this undersampled region. Next, to remove anomalous influences of sea ice on our proxy estimates (in particular, the influence of sea ice on the $\delta^{18} \mathrm{O}$ of seawater ${ }^{21}$ ) we removed all records situated at locations where pre-industrial mean annual SSTs were less than $0^{\circ} \mathrm{C}$ (a value assumed to roughly approximate the perennial sea ice edge), as estimated from the World Ocean Atlas 2013 product ${ }^{42}$. Following ref. ${ }^{20}$, we omitted all $U_{37}^{K^{\prime}}$ records situated north of $70^{\circ} \mathrm{N}$ or within the modern Arctic sea ice zone, due to known biases in the alkenone temperature proxy that likely arise from lipid contributions from 
Isochrysidales species living in sea ice ${ }^{43}$. We also removed two western Atlantic sites, OCE326GGC26 $\left(43^{\circ} 29^{\prime} \mathrm{N}, 54^{\circ} 52^{\prime} \mathrm{W}\right)$ and OCE326-GGC30, $\left(43^{\circ} 53^{\prime} \mathrm{N}, 62^{\circ} 48^{\prime} \mathrm{W}\right.$; ref. $\left.{ }^{44}\right)$. While these $U_{37}^{K^{\prime}}$ records have been featured in prior mean global Holocene temperature reconstructions ${ }^{6}$, they show an extremely large (up to $10^{\circ} \mathrm{C}$ ) cooling over the Holocene that most likely reflects a shift in the Gulf Stream/Labrador Current boundary ${ }^{44}$. This poses a problem for our data assimilation technique, because CESM1.2 does not put this sharp boundary in the same place as observations. Assimilation of these sites thus has a tendency to cause a large regional bias in SSTs. All told, our selection criteria resulted in the removal of 34 records.

Proxy-only global mean temperature reconstruction To provide a point of comparison for our data assimilation results, we generated a reconstruction of global mean temperature change relative to the pre-industrial using the screened (see above) proxy data, broadly following the methodology of ref. ${ }^{45}$. This was done by first estimating a "reference" pre-industrial proxy value for each site, and appending each value at the top of its respective $N \times 1$ proxy record. This produced an $\left(N_{i}+1\right) \times 1$ vector of proxy values for each site $i$, where the +1 denotes the appended preindustrial reference value. For sites with value(s) overlapping the last millennium (that is, $0-1$ ky BP), the pre-industrial reference was computed as the last millennium mean proxy value. For sites without last millennium overlap, pre-industrial reference proxy values were estimated by using the nearest core-top value ${ }^{19-22}$. All $\left(N_{i}+1\right) \times 1$ vectors were then calibrated to SSTs using the Bayesian inverse models ${ }^{19-22}$. For the $\delta^{18} \mathrm{O}_{c}$ and $\mathrm{TEX}_{86}$ models ${ }^{20,21}$ we used prior standard deviation values of $10^{\circ} \mathrm{C}$, while for the $U_{37}^{K^{\prime}}$ and $\mathrm{Mg} / \mathrm{Ca}$ models ${ }^{19,22}$ we used values of $5^{\circ} \mathrm{C}$ and $6^{\circ} \mathrm{C}$, respectively. All prior standard deviation values are conservative, and only minimally impact the posterior. The $\mathrm{Mg} / \mathrm{Ca}$ model, BAYMAG, also requires constraints on salinity, $\mathrm{pH}$, and bottom water calcite saturation $(\Omega)$. The BAYMAG package includes functions to estimate past changes in salinity and $\mathrm{pH}$. Briefly, following refs. ${ }^{22}$ and ${ }^{46}$, these functions scale the global sea level curve ${ }^{47}$ to an inferred LGM global change of $1.1 \mathrm{psu}$, then add this to the modern mean annual value of surface salinity for each site, as estimated from the World Ocean Atlas $2013^{42}$. Similarly, to 
estimate changes in $\mathrm{pH}$, BAYMAG scales the ice core $p \mathrm{CO}_{2}$ record ${ }^{48}$ to an inferred global increase of $0.13 \mathrm{pH}$ units during the LGM, and then adds this curve to the modern mean annual value of surface $\mathrm{pH}$ estimated from the Global Ocean Data Analysis Project version 2 (GLODAPv2; ${ }^{49}$ ). Following ref. ${ }^{22}, \Omega$ is estimated at each records' bathymetric depth using the GLODAPv2 product and assumed to be constant through time. The $\delta^{18} \mathrm{O}_{c}$ model, BAYFOX, requires constraints on the time-evolution of $\delta^{18} \mathrm{O}$ of seawater. For this, we first scaled the benthic stack of ref. ${ }^{50}$ to an estimated change in global $\delta^{18} \mathrm{O}$ of seawater (arising from changes in global ice volume) of $+1 \%$ at the LGM $(18 \mathrm{ka})$ relative to the pre-industrial following ref. ${ }^{51}$. This scaled curve was then added to the modern mean annual $\delta^{18} \mathrm{O}$ of seawater value ${ }^{52}$ and interpolated in time for each site.

The posterior SST estimates produced by the Bayesian inverse models are a matrix of dimension $\left(N_{i}+1\right) \times M$, where $M$ contains 1,000 possible SST histories and core-top reference values for each time entry $N_{i}+1$ of each $i$ site. These matrices were sorted from least to greatest along dimension $M$, which preserves the "shape" of the time series, after which a normally distributed analytical uncertainty of $\mathcal{N}\left(0,0.5^{\circ}\right)$ was added back to the sorted ensembles to account for laboratory precision (see also refs. ${ }^{10}$ and ${ }^{45}$ ). Finally, we converted each of our records to SST anomaly units relative to pre-industrial values (which we define as the last 1 ka mean for each site) by subtracting the first row of the $\left(N_{i}+1\right) \times M$ matrix (the pre-industrial core-top estimate) from the remaining rows to generate an $N_{i} \times M$ matrix of SST anomalies.

In order to produce a global mean surface air temperature (GMST) anomaly curve, SST anomaly values and associated ages were randomly drawn from our ensemble of $M$ posterior values and our ensemble of 1,000 age models, respectively, and then sorted into contiguous $200-\mathrm{yr}$ bins spanning back to $24 \mathrm{ka}$. If more than one data point per record occurred in a given $200 \mathrm{yr}$ bin, those SST data points were averaged, to ensure that higher-resolution records did not bias the bin. Following refs. ${ }^{4,10}$ and ${ }^{53}$, the data within each time bin were binned by latitude, with the bin size randomly selected between 2.5 and $20^{\circ}$, and then global average SST (GSST) was 
computed as the latitudinally weighted zonal average. Following ref. ${ }^{5}$, GSST was then scaled by a value randomly chosen between 1.96 and 2.92 to transform the values to GMST. This Monte Carlo process was repeated 10,000 times, to propagate errors arising from the SST estimation, age modeling, latitudinal weighting, and GSST to GMST scaling.

Climate model simulations The climate model priors are drawn from newly developed and preexisting climate simulations with the water isotope-enabled Community Earth System Model, versions 1.2 and 1.3 (iCESM1.2 and iCESM1.3). CESM1.2 is an updated version of CESM1 ${ }^{54}$, and CESM1.3 contains further updates to the gravity wave scheme, cloud microphysics, and radiation 55. Critical for our purposes, iCESM explicitly simulates the transport and transformation of stable water isotopes (e.g. $\mathrm{H}_{2}^{18} \mathrm{O}, \mathrm{HDO}$ ) in all of the component models, and has been shown to reproduce key features of climate and isotopes in present-day and paleoclimate observations ${ }^{23}$. All of the iCESM simulations have a horizontal resolution of $1.9 \times 2.5^{\circ}$ (latitude $\times$ longitude) in the atmosphere and land, and a nominal $1^{\circ}$ in the ocean. Preexisting iCESM simulations used in this study include the pre-industrial and LGM simulations with iCESM1.3 ${ }^{56}$, the pre-industrial, $3 \mathrm{ka}, 18 \mathrm{ka}$, and LGM simulations with iCESM1.2 ${ }^{10}$, and the Last Millennium simulation with iCESM1.2 57 (Extended Data Table 1).

In addition, we developed new time-slice simulations using iCESM1.2 of 16, 14, 12, 9, and 6 ka before present (Extended Data Table 1). For each time slice, the greenhouse gases $\left(\mathrm{CO}_{2}, \mathrm{CH}_{4}\right.$, and $\mathrm{N}_{2} \mathrm{O}$ ) were set to 200-year averages centered around the corresponding time from ice core reconstructions ${ }^{58-60}$. Orbital parameters followed ${ }^{30}$. Ice sheet forcing was prescribed according to the ICE-6G reconstruction ${ }^{39}$, including effects from changes in land elevation and surface properties and the land-sea mask due to sea-level variations. For each time-slice simulation, ocean temperature and salinity were initialized from published CESM1.2 simulations when available ${ }^{61}$. Seawater $\delta^{18} \mathrm{O}\left(\delta^{18} \mathrm{O}_{s w}\right)$ was initialized from the slice before, e.g. $\delta^{18} \mathrm{O}_{s w}$ of 18 ka branched from $21 \mathrm{ka}$. A spatially uniform correction was applied to salinity and $\delta^{18} \mathrm{O}_{s w}$ to account for the ice- 
volume effect. The correction terms were derived by scaling changes in the global volume-mean salinity and $\delta^{18} \mathrm{O}_{s w}$ between 21 and $0 \mathrm{ka}$ by the corresponding change in the global mean sea level 47. Global volume-mean salinity and $\delta^{18} \mathrm{O}_{s w}$ were 34.7 and $35.7 \mathrm{~g} \mathrm{~kg}^{-1}$ and 0.05 and $1.05 \%$ in the 0 and 21 ka simulations, respectively ${ }^{62}$. The iCESM1.2 time-slice simulations used pre-industrial aerosol emissions because of the lack of reliable global reconstructions ${ }^{63}$. For a similar reason, the simulations used the pre-industrial vegetation cover except for the 9 and 6 ka slices (see description below). All these time-slice simulations were run for 900 years.

A "Green Sahara" was implemented in both the 9 and 6 ka simulations by prescribing a $100 \%$ spatial coverage of shrub and $\mathrm{C} 4$ grass at $10-25^{\circ} \mathrm{N}$ and $25-35^{\circ} \mathrm{N}$, respectively. In addition, $\mathrm{C} 3$ grass over the Northern Hemisphere high latitude regions (northward of $50^{\circ} \mathrm{N}$ ) was replaced with boreal tree in the $6 \mathrm{ka}$ simulation. These vegetation changes were developed following recommendations from the Paleoclimate Modeling Intercomparison Project and represent maximum possible vegetation expansion over the Sahara and the Northern Hemisphere according to the pollen and macro-fossil evidence ${ }^{64}$. To sample the uncertainty from vegetation, an additional 6 ka simulation was performed for 400 years with the pre-industrial vegetation cover, as another end-member of the mid-Holocene vegetation forcing. All the iCESM1.2 time slice simulations were run with a prescribed satellite phenology in the land model due to the overall poor simulation of vegetation processes with a prognostic phenology ${ }^{65}$. The satellite observation-derived vegetation phenology included leaf area and stem area indices, and vegetation heights.

In addition, two water hosing experiments were performed within the 16 and 12 ka slices, respectively, to provide prior climate states for the millennial-scale events of the last deglaciation (i.e., Heinrich 1 and the Younger Dryas). In the hosing experiments, $0.25 \mathrm{~Sv}$ of freshwater with a $\delta^{18} \mathrm{O}$ composition of $-30 \%$ (VSMOW) were applied over the northern North Atlantic $\left(50-70^{\circ} \mathrm{N}\right)$. These experiments were run for 200 years. Prior to using the simulations in our data assimilation, a paleoclimate calendar adjustment was applied to the monthly model output for all time slices to 
account for the effect of changing months on seasonal climatic expressions ${ }^{66}$.

Paleoclimate data assimilation The data assimilation method incorporates an offline ensemble square root Kalman Filter approach, following the methodology of ref. ${ }^{10}$ using the data assimilation Matlab code package DASH version 3.6.1 (source code available at https://github. com/JonKing 93/DASH). We refer the reader to this previous work for a full mathematical description. Briefly, the method combines a set of prior climate states from our model simulations ( $X_{\text {prior }}$ ) with new information from the proxy observations (the "innovation", $Y_{o b s}-Y_{e s t}$ ) to compute a "posterior" matrix of assimilated past climate states, $X_{\text {post }}$, using the following Kalman filter update equation:

$$
X_{\text {post }}=X_{\text {prior }}+K\left(Y_{o b s}-Y_{e s t}\right) .
$$

$X_{\text {prior }}$ is a $N \times M$ matrix of prior climate states from iCESM, where dimension $N$ contains the model grid point data for SST and SSS (both at monthly and mean-annual resolution), and meanannual surface air temperature (SAT), $\delta^{18} \mathrm{O}$ of surface seawater $\left(\delta^{18} \mathrm{O}_{s w}\right)$, precipitation amountweighted $\delta^{18} \mathrm{O}\left(\delta^{18} \mathrm{O}_{p}\right)$, and mean-annual precipitation rate collapsed into a concatenated vertical "state vector," and dimension $M$ represents the number of state vector ensemble members.

The $P \times M$ matrix $Y_{o b s}$ consists of $P$ globally dispersed $\delta^{18} \mathrm{O}_{c}, \mathrm{Mg} / \mathrm{Ca}, U_{37}^{K^{\prime}}$, and $\mathrm{TEX}_{86}$ proxy observations, repeated column-wise $M$ times for tractability. The matrix $Y_{\text {est }}$ contains the corresponding set of $P$ proxy estimates, generated from the model output from each $M$ state using our Bayesian forward models. For details concerning the Bayesian models, the readers are referred to the original publications ${ }^{19-22}$. In brief, the forward model for $\delta^{18} \mathrm{O}_{c}$ requires monthly SST and mean annual $\delta^{18} \mathrm{O}_{s w}$. These $\delta^{18} \mathrm{O}_{c}$ values are computed on a species- and growing season-specific basis ${ }^{21}$ that allows us to explicitly account for foraminiferal seasonal preferences in our forward model proxy estimates. Both the $U_{37}^{K^{\prime}}$ and TEX $\mathrm{X}_{86}$ models require only SST as inputs, with the former requiring monthly SST due to the seasonal response of $U_{37}^{K^{\prime}}$ production in the North Pacific, the North Atlantic, and the Mediterranean ${ }^{20}$, and the latter only mean annual SST ${ }^{19}$. Finally, the 
forward model for $\mathrm{Mg} / \mathrm{Ca}$ requires both monthly SST and SSS to compute species-specific growing season $\mathrm{Mg} / \mathrm{Ca}$ values, in addition to sea-surface $\mathrm{pH}$, bottom water calcite saturation state $(\Omega)$, and the laboratory cleaning method. The latter is provided in the original publications, and SST and SSS are drawn from iCESM output. For $\mathrm{pH}$ and $\Omega$, we follow the same procedure as the proxy-only reconstruction (described above).

The innovation $\left(Y_{o b s}-Y_{e s t}\right)$ represents the new information from the observations not already provided by the prior estimates. As shown in Eq. (1), these values are weighted by the $N \times P$ matrix $K$, the Kalman gain, which takes the general form:

$$
K=\operatorname{cov}\left(X_{\text {prior }}, Y_{\text {est }}\right) *\left[\operatorname{cov}\left(Y_{\text {est }}, Y_{\text {est }}\right)+R\right]^{-1}
$$

where "cov" denotes the covariance expectation. The $P \times P$ matrix $R$ prescribes the error covariance associated with each proxy observation. Thus, the Kalman gain weights the innovation by the covariance of the forward-modeled proxy estimates with the prior climate states and the uncertainties of the prior-estimated proxy ensemble and the proxy observations. In our case, $R$ is diagonal; i.e., the errors are presumed to be independent. $R$ is user-defined, but ideally based on an estimate of "true" proxy uncertainties. Following ${ }^{10}$, who systematically tested in the impact of different values of $R$ on the posterior, we use the error values output from our Bayesian forward models scaled by $1 / 5$, but further refine this by specifying a slightly different scaling factor for each proxy type. To determine these proxy-specific factors, for each record we performed jack-knife (leave one record out) and "only-one record" assimilation experiments (no $R$ scalings applied) in order to assess the ability of any particular record to predict all others when that record was either removed, or solely retained, respectively. From these experiments, we then ranked each record by validating the only-one and all-but-one reconstructions against the non-assimilated proxies. This allowed assessment for the percent of tests for which this proxy resulted in "improvement" (as denoted by the ratio of the posterior to prior squared error of all predicted, independent proxies, 
where a ratio less than unity indicates improvement). Using these rankings for each proxy type, we then weighted each proxy-specific scaling factor by the improvement factor, and subsequently weighted these rankings by total record count to maintain an average $R$-scaling of $1 / 5$ across all available proxy records. The specific scaling factors that we calculated were $r_{u k}=3.13^{-1}, r_{t e x}=$ $1.36^{-1}, r_{m g c a}=2.86^{-1}$, and $r_{18 o}=7.27^{-1}$, indicating $\delta^{18} \mathrm{O}_{c}$ to be the most reliable (and numerous) proxy type.

Following refs. ${ }^{10}$ and ${ }^{18}$, we applied covariance localization to the assimilation to limit spurious relationships between proxies and far-field regions. Validation testing suggested that a 24,000 km localization radius provided optimal posterior results for our dataset (see "Internal and external validation testing" below). This differs from ref. ${ }^{10}$, who used a more narrow $12,000 \mathrm{~km}$ localization. The improvement we find using broader localization likely relates to the fact that fewer proxies are assimilated here per time step than in ref. ${ }^{10}$.

For computing our full 24 kyr "Last Glacial Maximum Reanalysis" (LGMR) product, we calculated $X_{\text {post }}$ at 200-year increments using the following approach. First, we selected $80 \%$ of our proxy records at random for inclusion in our assimilation, with the remaining $20 \%$ of records withheld for statistical validation (see "Internal and external validation testing" below). For each record, we randomly prescribed an age scale by drawing from the 1,000 viable posterior BACONderived age models. Second, for each 200-year interval, $Y_{\text {obs }}$ was compiled as all of the available proxy data points whose ages are within the bounds of the current reconstruction age-interval. When multiple data points from a single record occurred within a given 200-year age-interval, these values were averaged. We then randomly selected $M=60$ state vector ensembles from the iCESM output using a transient "evolving prior" approach (see below), and used the Bayesian forward models to produce the matrix $Y_{\text {est }}$. $X_{\text {post }}$ was then computed from $Y_{\text {obs }}$ and $Y_{\text {est }}$ (Eq. 1) with $R$ in the Kalman gain (Eq. 2) scaled to the appropriate proxy type. Finally, this process was repeated for a total 300 times for each time interval, to create a 300-member LGM-to-present 
ensemble of posterior states. This Monte Carlo procedure ensures that proxy, age-model, and model prior uncertainties are included in the assimilated product. Since the age model uncertainties in particular can be on the order of centuries, this sampling procedure has the effect of smoothing the posterior time series on sub-millennial timescales.

Assimilation of the LGM-to-present climate evolution at 200-year intervals directly reflects our underlying proxy data compilation. $\sim 96 \%$ of the proxy records have a median resolution that is higher than 200 years (Extended Data Figure 1). However, if all $>60,000$ compiled data points are considered together, $>90 \%$ of the paleoclimate data have sample resolutions of $\leq 200$ years. While ideally, the amount of time represented by the model prior would also equal 200 years, this would have considerably limited the number of model priors available (a maximum of 58 prior states across our all iCESM time-slice simulations, and as few as 4 priors for a given interval; Extended Data Table 1). In order to increase the number of iCESM priors available for assimilating our marine proxies while still roughly adhering to our reconstruction interval, we instead used 50year average priors, following ref. ${ }^{10}$. Prior experimentation by ref. ${ }^{10}$ showed only marginal differences in LGM and pre-industrial posteriors once time-averaging of our iCESM prior fields exceed interannual time periods, justifying this choice.

Assimilating Earth's transient climate evolution between two fundamentally different glacial versus interglacial states presents a unique obstacle for offline paleoclimate data assimilation (which has largely focused on reconstructing the climate evolution of the Common Era ${ }^{18}$, a relatively stable background climate state ${ }^{9}$ ). In terms of Bayesian inference, the challenge is adequately assigning a collection of iCESM priors at each LGM-to-present reconstruction interval that reflects a reasonable prior belief in their viability. For example, a time interval in the late Holocene should not include glacial prior states that contain a Laurentide ice sheet, as the latter induces fundamental changes in spatial covariance that are not realistic for a deglaciated climate state. Conversely, deglacial prior states might include a range of possible Laurentide configurations. 
To address this issue, we developed an "evolving prior" approach. For each 200-yr interval, we defined a Normal probability density function (PDF) with a $1 \sigma$ range of 4,000 years and a maximum cutoff range of $3 \sigma$ ( $\pm 12,000$ years). The PDF is truncated to the range of our target time interval (24-0 ka), such that for the tail ends of the reconstruction interval, the PDF ends up being half-Normal. We then sampled 60 prior ages from this PDF and rounded them to $0,3,6,9,12$, $14,16,18$, or $21 \mathrm{ka} \mathrm{BP}$, the discrete time-slice intervals at which iCESM simulations are available (Extended Data Table 1). For each randomly drawn and rounded age, a model prior was selected (with replacement) from its corresponding iCESM time-slice simulation.

The $1 \sigma$ range of 4,000 years was chosen to balance the need to include adequate variability in the prior while still excluding model priors that are not physically justified (i.e., the inclusion of LGM priors when assimilating mid-late Holocene climatic states, and vice-versa). Validation testing further indicated that this length scale was near-optimal, and also results in substantial improvement over an "agnostic" prior sampling scheme (e.g., one that assigns equal probability of including a prior from any given iCESM timeslice; see "Internal and external validation testing", below).

Internal and external validation testing Statistical validation and tuning of our LGMR product was conducted in two ways, referred hereafter as "internal" and "external" validation. The first approach ("internal" validation) involves withholding $20 \%$ of the marine proxies per iteration (see "Paleoclimate data assimilation", above), and then using the posterior SST, SSS, and $\delta^{18} \mathrm{O}_{s w}$ fields to forward model the withheld proxy records. These predicted proxy records were then compared with the actual proxy records using standard skill diagnostics: the coefficient of efficacy (CE; a value between $-\infty$ and 1 , where a value $>0$ is conventionally taken to represent skill over climatology), the squared product moment coefficient $\left(R^{2}\right)$, and the root mean square error of prediction $(R M S E P)$. The computation of multiple posterior ensembles (i.e., $N=300$ ), each with $20 \%$ withholding, implies each proxy record was randomly withheld and internally validated on 
average 60 times. These tests yield, on average, CE values that are greater than 0 with no obvious signs of systematic spatial biasing, indicative of skill in our posterior assimilation above our evolving iCESM prior fields. On a global basis all posterior-predicted proxies exhibit a strong correspondence to observed values with $R^{2}>0.95$ and slopes within $5 \%$ of their respective 1:1 lines (Extended Data Figure 2), indicating a lack of systematic bias in the LGMR oceanic climatologies.

Following ref. ${ }^{10}$, we also use independent ice core and speleothem records of $\delta^{18} \mathrm{O}_{p}$ to externally validate the LGMR. In this more stringent analysis, we compare posterior $\delta^{18} \mathrm{O}_{p}$ to published ice core $\delta^{18} \mathrm{O}$ (which is taken as a direct indicator of precipitation-weighted mean-annual $\delta^{18} \mathrm{O}_{p}$, given that post-depositional processes such as isotopic diffusion ${ }^{67}$ and sublimation ${ }^{68}$ do not typically impact ice core record integrity across centennial and longer time scales) and speleothem $\delta^{18} \mathrm{O}$, which is first converted to $\delta^{18} \mathrm{O}_{p}$ via the methodology of ref. ${ }^{69}$ (see also ref. ${ }^{10}$ ). For the speleothem data, we used the SISAL version $1 \mathrm{~b}$ database ${ }^{70}$. Records were included in our compilation solely on the basis that they span at least 18,000 years: that is, at least three-quarters of the LGMR reconstruction interval, ensuring overlap with the deglacial period (ca. 17-9 ka; Fig. 2). Record-specific details are provided in Extended Data Table 2. Following ref. ${ }^{10}$, we focus on $\delta^{18} \mathrm{O}_{p}$ deviations $\left(\Delta \delta^{18} \mathrm{O}_{p}\right)$, which we generate by differencing all $\delta^{18} \mathrm{O}_{p}$ values at each time slice interval relative to the $0 \mathrm{ka}$ baseline. This approach is premised on the expectation that $\delta^{18} \mathrm{O}_{p}$ deviations should be adequately captured by LGMR ${ }^{10}$ despite known mean $\delta^{18} \mathrm{O}_{p}$ biases in $\mathrm{iCESM}^{23}$. We then compare both prior and posterior $\Delta \delta^{18} \mathrm{O}_{p}$ with observed $\Delta \delta^{18} \mathrm{O}_{p}$ at the iCESM timeslice intervals $(3,6,9,12,14,16,18$, and $21 \mathrm{ka} \mathrm{BP})$ using our statistical diagnostics of covariance and prediction error $\left(R^{2}\right.$ and $\left.R M S E P\right)$. Positive $\Delta \mathrm{R}^{2}$ (i.e., a stronger relationship with observed values in LGMR vs. the prior) and negative $\triangle R M S E P$ (i.e., reduced prediction error in LGMR vs. the prior) imply improvement in our LGMR posterior relative to the iCESM priors.

Overall, this external validation test indicates that LGMR substantially improves over the 
prior, with a nearly $30 \%$ error reduction $\left(R M S E P_{\text {prior }}=2.60 \%\right.$; $\left.R M S E P_{\text {posterior }}=1.91 \%\right)$ and approaching $2 \times$ greater variance explained in with our posterior-predicted values relative to the prior $\left(R_{\text {prior }}^{2}=0.37 ; R_{\text {posterior }}^{2}=0.62\right)$. Although much of the improvement is driven by ice core $\Delta \delta^{18} \mathrm{O}_{p}$ estimates (Extended Data Figure 3 and Extended Data Figure 4), offsets with speleothem $\Delta \delta^{18} \mathrm{O}_{p}$ observations are also strongly reduced in LGMR relative to iCESM. The comparably poor temporal covariance shown by global speleothem $\Delta \delta^{18} \mathrm{O}_{p}$ values relative to ice cores (Extended Data Figure 4; Extended Data Table 2) may reflect local-scale influences on speleothem $\delta^{18} \mathrm{O}_{p}$ records, such as groundwater storage, mixing, recharge, and residence time variations; subgridscale topographic and (or) precipitation influences; and uncertainties arising from indirectly inferring $\delta^{18} \mathrm{O}_{p}$ from $\delta^{18} \mathrm{O}_{\text {calcite }}$ or $\delta^{18} \mathrm{O}_{\text {aragonite }}$ measurements ${ }^{69}$. In addition, the iCESM prior range of $\delta^{18} \mathrm{O}_{p}$ across the LGM to present in the tropics is considerably smaller than in the high latitudes (e.g., Extended Data Figure 4), which might restrict the posterior solutions for the speleothems (c.f. ref. ${ }^{10}$ ).

We used external validation testing to choose both the covariance localization radius and evolving prior $1 \sigma$ range (see "Paleoclimate data assimilation" for description of each). Between the two, our tests show that LGMR is most sensitive to the choice of localization radius. We tested values between 6,000 and infinite (i.e., no localization) $\mathrm{km}$ and found a relatively broad localization cutoff $(24,000 \mathrm{~km})$ is near-optimal (Extended Data Table 3$)$. In contrast, LGMR shows comparably less sensitivity to choice of the $1 \sigma$ range for sampling iCESM priors, with acceptable external validation scoring for values between $1 \sigma=2,000-6,000$ years (Extended Data Table 3). For our final LGMR product we chose a value of $1 \sigma=4000$ years as this was shown to provide nearoptimal validation scoring (Extended Data Table 3), while also constituting a reasonable "middle ground" between enabling adequate variance amongst iCESM model priors throughout the last 24 kyr while excluding physically unjustifiable states (see discussion above). 
Proxy specific reconstructions We assess the influence of each proxy type on our results by conducting proxy-specific reconstructions of LGM-to-present GMST using both our "proxy-only" (see, "Proxy only global mean temperature reconstruction", above) as well as data assimilation (see, "Paleoclimate data assimilation", above) approaches. Due to the limited number of TEX 86 records (28), our analysis is focused on $U_{37}^{K^{\prime}}, \mathrm{Mg} / \mathrm{Ca}$, and $\delta^{18} \mathrm{O}_{c}$. Overall, we find that GMSTs are, on average, mildly warmer in our proxy-only reconstructions than in our data assimilation results across all proxy types, a difference that is especially pronounced during the early Holocene (ca 9-8 ka) period (Extended Data Figure 6). Uncertainties are largest for the proxy-only $\mathrm{Mg} / \mathrm{Ca}$ reconstruction, which appears to be the least internally consistent of the six reconstructions (Extended Data Figure 6c) implying that it is the least reliable proxy type. Most likely, this reflects the multivariate sensitivity of this proxy. In particular, since our iCESM simulations do not include an interactive ocean carbon cycle, we make basic assumptions about surface water $\mathrm{pH}$ and bottom water saturation to forward model $\mathrm{Mg} / \mathrm{Ca}$. Bottom water saturation $(\Omega)$ in particular is the second-most important environmental influence on foraminiferal $\mathrm{Mg} / \mathrm{Ca}$ after temperature ${ }^{22}$, and must have changed dramatically across the deglacial transition. Unfortunately, we lack good constraints on $\Omega$, so we must assume that it is constant through time. Despite these concerns, we do not have probable cause nor reason to consider $\mathrm{Mg} / \mathrm{Ca}$ inherently "incorrect," and it is clear from the proxy-specific experiments that data assimilation draws the $\mathrm{Mg} / \mathrm{Ca}$ data closer to a solution that is consistent with $U_{37}^{K^{\prime}}$ and $\delta^{18} \mathrm{O}_{c}$ (Extended Data Figure 6d).

The proxy-only $\mathrm{Mg} / \mathrm{Ca}$ and $U_{37}^{K^{\prime}}$ reconstructions show cooling across the Holocene since about $8 \mathrm{ka}$ (Extended Data Figure 6b and c), a feature that translates into the full proxy-only reconstruction (Fig. 4a). However, these trends are eliminated after assimilating the same proxy data with iCESM; for $U_{37}^{K^{\prime}}$, the Holocene cooling trend switches entirely to Holocene warming (Extended Data Figure 6b). Similarly, for $\delta^{18} \mathrm{O}_{c}$ we find that the stable Holocene temperature evolution implied by the proxy-only method becomes a warming trend when assimilated with iCESM. Collectively, the consistency we observe amongst our data assimilated results implies a 
cold early Holocene and stable mid-late Holocene is a dynamically consistent solution under the confines of our underlying proxy-model covariance, a finding that is all the more remarkable given that this isn't an obvious feature of our iCESM priors (Fig. 4a and Extended Data Figure 6).

Timing of last deglacial and interglacial onset We quantify the onset timing of the last deglacial and current interglacial periods by considering GMST of the last $24 \mathrm{ka}$ as a linearly contiguous three part sequence: a glacial period, a deglacial period, and an interglacial period. We incorporate the Bayesian changepoint methodology of ${ }^{71}$ to isolate the two leading changepoints separating these three periods, accounting for time and temperature uncertainty through Monte Carlo randomization $(n=10,000)$. In each iteration, we produce a surrogate 24 ka GMST time series by 1) normal random sampling of temperature for each 200-yr interval, using the LMGR ensemble mean and standard deviation and 2) uniform random sampling an associated age for each 200-yr interval. For each resultant time- and temperature-perturbed global mean temperature time series, we then determine the location of the two changepoints; for each iteration, we assume that the leading changepoint denotes the deglaciation onset and that the second changepoint denotes the interglacial onset. This analysis indicates a deglaciation onset at $17.2 \mathrm{ka}(18.7-16.4 \mathrm{ka} 95 \%$ confidence interval), and an interglacial onset at 9.2 (8.3-11.0) ka (Fig. 2).

Contextualizing the rate and magnitude of modern warming In order to compare the magnitude and rate of industrial-era warming (from the HadCRUT5 product ${ }^{11}$ ) to global temperature changes estimated by LGMR, we first adjusted the LGMR and HadCRUT5 GMST anomalies to a common, overlapping frame of reference. This was accomplished by re-centering GMST estimates from the Last Millennium Reanalysis (LMR) v2.1 ${ }^{18}$ as anomalies relative to 1000-1850 CE, and then adjusting LGMR and HadCRUT5 to this LMR frame of reference during their respective overlapping periods: 1000-1950 CE for LGMR and 1850-2000 CE for HadCRUT5. Next, in order to directly compare decadal-mean HadCRUT5 GMST values to LGMR GMST values, we adjusted the latter (LGMR) for decadal-to-centennial variance attenuation. This was done by individually 
scaling the LGMR GMST ensemble variance by the GMST decadal-to-centennial mean variance ratio from iCESM at each reconstruction time interval using our evolving prior approach (see Fig. 2). This adjustment produces pseudo decadal-mean GMST values for all LGMR time-intervals, rendering comparison to HadCRUT5 decadal-mean GMST more direct and conservative. Comparison between the decadal-adjusted LGMR and HadCRUT5 indicates that decadal mean GMST exceeded the range $\left(>99^{\text {th }}\right.$ percentile) of Holocene values by the turn of the 21 st century (20002009; Fig. 2). During the most recent decade (2010-2019), GMST exceeded maximum Holocene values by a more considerable margin: $>0.5^{\circ} \mathrm{C}$, corresponding to $+1.4^{\circ} \mathrm{C}$ above mean Holocene GMST.

To compare the centennial-scale rate of temperature change in LGMR to HadCRUT5, we randomly sampled GMST $(n=10,000)$ from the decadal-adjusted LGMR for each time interval across the deglaciation (ca. 17.2-9.2 ka; see "Timing of last deglacial and interglacial onset", above), which contains the largest and most rapid changes in GMST during the last 24 kyr (Fig. 2). These randomly sampled values of GMST were then used to estimate rates of change moving forward in time across adjoining time intervals, allowing us to develop a large distribution of possible deglacial warming rates. Our analysis shows that by the 20th century (1900-1999 CE), the rate of industrial era warming $\left(0.72^{\circ} \mathrm{C}_{\text {century }}{ }^{-1}\right)$ exceeded the $99^{\text {th }}$ percentile of composited warming rates for all time intervals of the deglaciation. In the ensuing (most-recent) two decades, the rate of centennial-scale GMST warming has risen by an additional $\sim 36 \%\left(0.98^{\circ} \mathrm{C}_{\text {century }}^{-1}\right.$ for the period 1920-2019 CE; Extended Data Figure 8b), thus recently exceeding the $99^{\text {th }}$ percentile of each individual reconstructed deglacial time interval (Extended Data Figure 8c).

Code availability The MATLAB code used for the reconstruction (DASH) are publicly available (https://github.com/JonKing93/DASH), as are all accompanying Bayesian proxy forward models (BAYSPAR, BAYSPLINE, BAYFOX, and BAYMAG) used in this study (https: // github. com/jesstierney). The iCESM1.2 model code is available at https: / / github. 
com/NCAR/iCESM1. 2.

Data availability LGMR and associated proxy data will be made publicly available pending acceptance of this manuscript. 


\section{Methods References}

40. Reimer, P. J. et al. IntCal13 and Marine13 Radiocarbon Age Calibration Curves 0-50,000 Years cal BP. Radiocarbon 55, 1869-1887 (2013).

41. Blaauw, M. \& Christen, J. A. Flexible paleoclimate age-depth models using an autoregressive gamma process. Bayesian Anal. 6, 457-474 (2011).

42. Locarnini, R. A. et al. World ocean atlas 2013. Volume 1, Temperature (2013).

43. Wang, K. J. et al. Group 2i Isochrysidales produce characteristic alkenones reflecting sea ice distribution. Nature Communications 12, 1-10 (2021).

44. Sachs, J. P. Cooling of Northwest Atlantic slope waters during the Holocene. Geophysical Research Letters 34 (2007).

45. Tierney, J. E., Haywood, A. M., Feng, R., Bhattacharya, T. \& Otto-Bliesner, B. L. Pliocene Warmth Consistent With Greenhouse Gas Forcing. Geophysical Research Letters 46, 91369144 (2019).

46. Gray, W. R. \& Evans, D. Nonthermal Influences on $\mathrm{Mg} / \mathrm{Ca}$ in Planktonic Foraminifera: A Review of Culture Studies and Application to the Last Glacial Maximum. Paleoceanography and Paleoclimatology 34, 306-315 (2019).

47. Lambeck, K., Rouby, H., Purcell, A., Sun, Y. \& Sambridge, M. Sea level and global ice volumes from the Last Glacial Maximum to the Holocene. Proceedings of the National Academy of Sciences 111, 15296 LP - 15303 (2014).

48. Bereiter, B. et al. Revision of the EPICA Dome C CO2 record from 800 to $600 \mathrm{kyr}$ before present. Geophysical Research Letters 42, 542-549 (2015).

49. Olsen, A. et al. The Global Ocean Data Analysis Project version 2 (GLODAPv2) - an internally consistent data product for the world ocean. Earth Syst. Sci. Data 8, 297-323 (2016). 
50. Lisiecki, L. E. \& Raymo, M. E. A Pliocene-Pleistocene stack of 57 globally distributed benthic $\delta 180$ records. Paleoceanography 20 (2005).

51. Schrag, D. P., Hampt, G. \& Murray, D. W. Pore Fluid Constraints on the Temperature and Oxygen Isotopic Composition of the Glacial Ocean. Science 272, 1930 LP - 1932 (1996).

52. LeGrande, A. N. \& Schmidt, G. A. Global gridded data set of the oxygen isotopic composition in seawater. Geophysical Research Letters 33 (2006).

53. Zhu, J., Poulsen, C. J. \& Tierney, J. E. Simulation of Eocene extreme warmth and high climate sensitivity through cloud feedbacks. Science advances 5, eaax1874 (2019).

54. Hurrell, J. W. et al. The Community Earth System Model: A Framework for Collaborative Research. Bulletin of the American Meteorological Society 94, 1339-1360 (2013).

55. Meehl, G. A. et al. Effects of Model Resolution, Physics, and Coupling on Southern Hemisphere Storm Tracks in CESM1.3. Geophysical Research Letters 46, 12408-12416 (2019).

56. Zhu, J. et al. Reduced ENSO variability at the LGM revealed by an isotope-enabled Earth system model. Geophysical Research Letters 44, 6984-6992 (2017).

57. Stevenson, S. et al. Volcanic Eruption Signatures in the Isotope-Enabled Last Millennium Ensemble. Paleoceanography and Paleoclimatology 34, 1534-1552 (2019).

58. Lüthi, D. et al. High-resolution carbon dioxide concentration record 650,000-800,000years before present. Nature 453, 379-382 (2008).

59. Loulergue, L. et al. Orbital and millennial-scale features of atmospheric $\mathrm{CH} 4$ over the past 800,000years. Nature 453, 383-386 (2008).

60. Schilt, A. et al. Atmospheric nitrous oxide during the last 140,000 years. Earth and Planetary Science Letters 300, 33-43 (2010). 
61. DiNezio, P. N. et al. Glacial changes in tropical climate amplified by the Indian Ocean. Science Advances 4, eaat9658 (2018).

62. Duplessy, J.-C., Labeyrie, L. \& Waelbroeck, C. Constraints on the ocean oxygen isotopic enrichment between the Last Glacial Maximum and the Holocene: Paleoceanographic implications. Quaternary Science Reviews 21, 315-330 (2002).

63. Kageyama, M. et al. The pmip4 contribution to cmip6-part 4: Scientific objectives and experimental design of the pmip4-cmip6 last glacial maximum experiments and pmip4 sensitivity experiments. Geoscientific Model Development 10, 4035-4055 (2017).

64. Otto-Bliesner, B. L. et al. The pmip4 contribution to cmip6-part 2: Two interglacials, scientific objective and experimental design for holocene and last interglacial simulations. Geoscientific Model Development 10, 3979-4003 (2017).

65. Lawrence, D. M. et al. Parameterization improvements and functional and structural advances in Version 4 of the Community Land Model. Journal of Advances in Modeling Earth Systems 3 (2011).

66. Bartlein, P. J. \& Shafer, S. L. Paleo calendar-effect adjustments in time-slice and transient climate-model simulations (PaleoCalAdjust v1.0): impact and strategies for data analysis. Geosci. Model Dev. 12, 3889-3913 (2019).

67. Jones, T. R. et al. Water isotope diffusion in the WAIS Divide ice core during the Holocene and last glacial. Journal of Geophysical Research: Earth Surface 122, 290-309 (2017).

68. Sokratov, S. A. \& Golubev, V. N. Snow isotopic content change by sublimation. Journal of Glaciology 55, 823-828 (2009).

69. Comas-Bru, L. et al. Evaluating model outputs using integrated global speleothem records of climate change since the last glacial. Clim. Past 15, 1557-1579 (2019). 
70. Atsawawaranunt, K. et al. The SISAL database: a global resource to document oxygen and carbon isotope records from speleothems. Earth Syst. Sci. Data 10, 1687-1713 (2018).

71. Ruggieri, E. A Bayesian approach to detecting change points in climatic records. International Journal of Climatology 33, 520-528 (2013).

72. Blunier, T. \& Brook, E. J. Timing of Millennial-Scale Climate Change in Antarctica and Greenland During the Last Glacial Period. Science 291, 109 LP - 112 (2001).

73. Stenni, B. et al. Expression of the bipolar see-saw in Antarctic climate records during the last deglaciation. Nature Geoscience 4, 46-49 (2011).

74. Watanabe, O. et al. Homogeneous climate variability across East Antarctica over the past three glacial cycles. Nature 422, 509-512 (2003).

75. Brook, E. J. et al. Timing of millennial-scale climate change at Siple Dome, West Antarctica, during the last glacial period. Quaternary Science Reviews 24, 1333-1343 (2005).

76. Stenni, B. et al. The deuterium excess records of EPICA Dome C and Dronning Maud Land ice cores (East Antarctica). Quaternary Science Reviews 29, 146-159 (2010).

77. Steig, E. J. et al. Synchronous Climate Changes in Antarctica and the North Atlantic. Science 282, 92 LP - 95 (1998).

78. Petit, J. R. et al. Climate and atmospheric history of the past 420,000 years from the Vostok ice core, Antarctica. Nature 399, 429-436 (1999).

79. Markle, B. R. et al. Global atmospheric teleconnections during Dansgaard-Oeschger events. Nature Geoscience 10, 36-40 (2017).

80. Vinther, B. M. et al. Synchronizing ice cores from the Renland and Agassiz ice caps to the Greenland Ice Core Chronology. Journal of Geophysical Research: Atmospheres 113, D08115 (2008). 
81. Stuiver, M. \& Grootes, P. M. GISP2 Oxygen Isotope Ratios. Quaternary Research 53, 277$284(2000)$.

82. Johnsen, S. J. et al. The $\delta 180$ record along the Greenland Ice Core Project deep ice core and the problem of possible Eemian climatic instability. Journal of Geophysical Research: Oceans 102, 26397-26410 (1997).

83. Andersen, K. K. et al. High-resolution record of Northern Hemisphere climate extending into the last interglacial period. Nature 431, 147-151 (2004).

84. Holmgren, K. et al. Persistent millennial-scale climatic variability over the past 25,000 years in Southern Africa. Quaternary Science Reviews 22, 2311-2326 (2003).

85. Novello, V. F. et al. Two Millennia of South Atlantic Convergence Zone Variability Reconstructed From Isotopic Proxies. Geophysical Research Letters 45, 5045-5051 (2018).

86. Cheng, H. et al. The climate variability in northern Levant over the past 20,000years. Geophysical Research Letters 42, 8641-8650 (2015).

87. Dutt, S. et al. Abrupt changes in Indian summer monsoon strength during 33,800 to 5500years B.P. Geophysical Research Letters 42, 5526-5532 (2015).

88. Ayliffe, L. K. et al. Rapid interhemispheric climate links via the Australasian monsoon during the last deglaciation. Nature Communications 4, 2908 (2013).

89. Partin, J. W., Cobb, K. M., Adkins, J. F., Clark, B. \& Fernandez, D. P. Millennial-scale trends in west Pacific warm pool hydrology since the Last Glacial Maximum. Nature 449, 452-455 (2007).

90. Cai, Y. et al. Variability of stalagmite-inferred Indian monsoon precipitation over the past 252,000 y. Proceedings of the National Academy of Sciences 112, 2954-2959 (2015). 
91. Fleitmann, D. et al. Timing and climatic impact of Greenland interstadials recorded in stalagmites from northern Turkey. Geophysical Research Letters 36, L19707 (2009).

92. Cruz, F. W. et al. Insolation-driven changes in atmospheric circulation over the past 116,000 years in subtropical Brazil. Nature 434, 63-66 (2005).

93. Hellstrom, J., McCulloch, M. \& Stone, J. A Detailed 31,000-Year Record of Climate and Vegetation Change, from the Isotope Geochemistry of Two New Zealand Speleothems. Quaternary Research 50, 167-178 (1998).

94. Grant, K. M. et al. Rapid coupling between ice volume and polar temperature over the past 150,000years. Nature 491, 744-747 (2012).

95. Cheng, H. et al. Climate change patterns in Amazonia and biodiversity. Nature Communications 4, 1411 (2013). 
Acknowledgements We thank B. Malevich for early discussions and explorations on LGM-to-present data assimilation, and M. Fox and N. Rapp for help in compiling the proxy data. We thank P. DiNezio for providing initial and boundary condition files for the CESM simulations, and B. Markle for assistance in compiling and sharing the ice core water isotope data. This study was supported by National Science Foundation (NSF) grant numbers AGS-1602301 and AGS-1602223, and Heising-Simons Foundation grant numbers 2016-012, 2016-014, and 2016-015. The CESM project is supported primarily by the NSF. This material is based upon work supported by the National Center for Atmospheric Research, which is a major facility sponsored by the NSF under Cooperative Agreement No. 1852977. Computing and data storage resources, including the Cheyenne supercomputer (doi:10.5065/D6RX99HX), were provided by the Computational and Information Systems Laboratory (CISL) at NCAR.

Author contributions M.B.O. conducted the data assimilation, led the analysis and interpretation of the results, and designed the figures. M.B.O. and J.E.T. led the writing of this paper. J.E.T. led the proxy data compilation. J.K. wrote the DASH code, based on methods and input by R.T. and G.J.H. J.Z. and C.J.P. planned and conducted the iCESM simulations. All authors contributed to the design of the study and the writing of this manuscript.

Competing interests The authors declare that they have no competing financial interests.

Correspondence Correspondence should be addressed to M.B.O. (mattosman@ arizona.edu). 

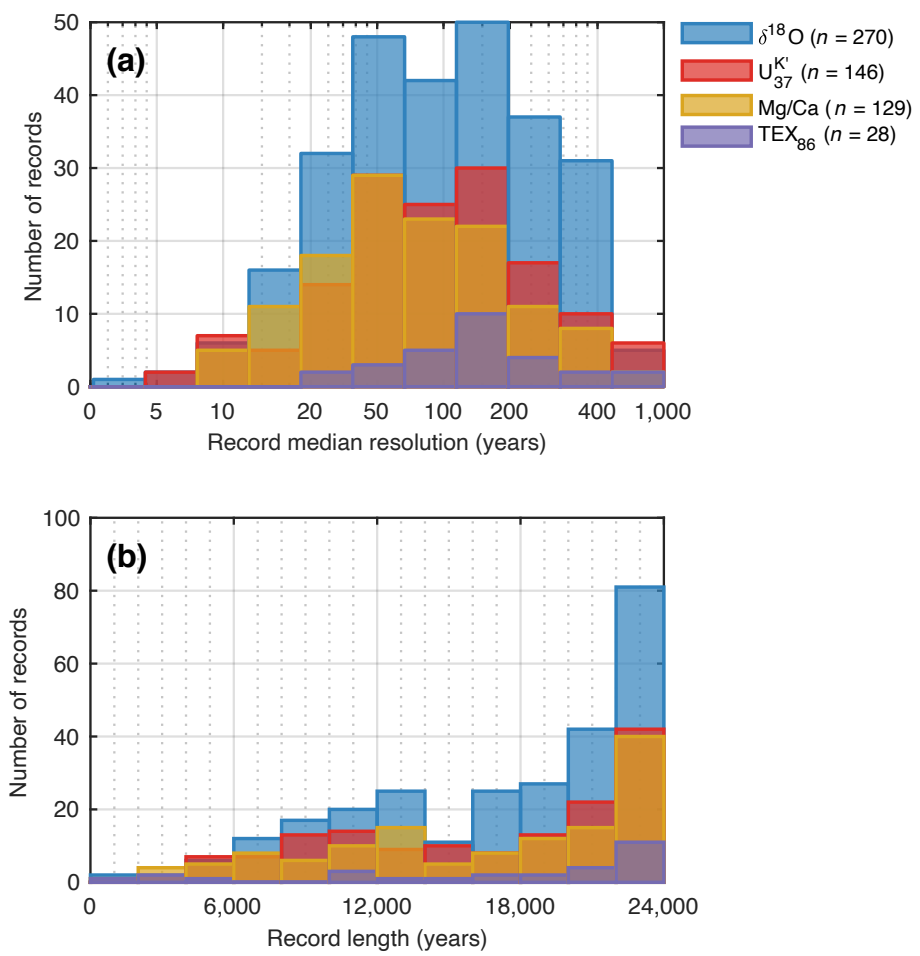

Extended Data Figure 1. Time resolution and temporal coverage of the SST proxy data compilation. (a). Histogram of record resolution (denoting the median sample resolution for each record), computed for each proxy type. (b) Histogram of record length for each proxy type. 
(a)

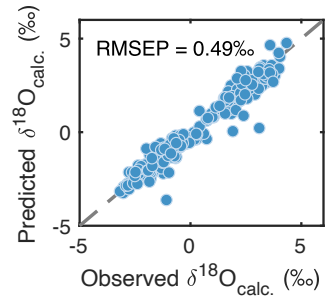

(b)

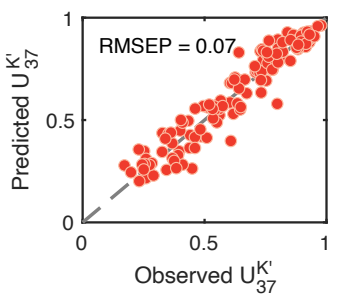

(c)

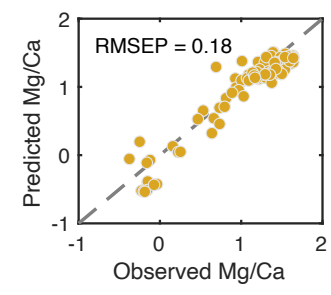

(d)

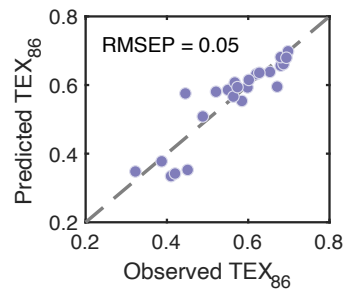

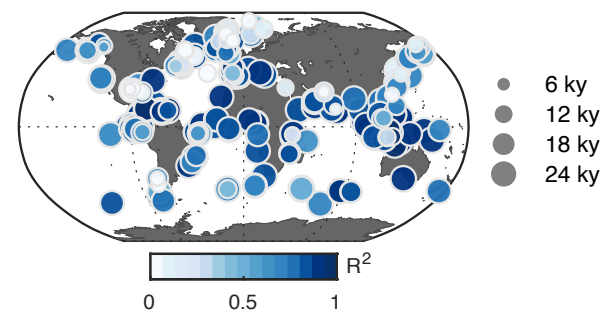
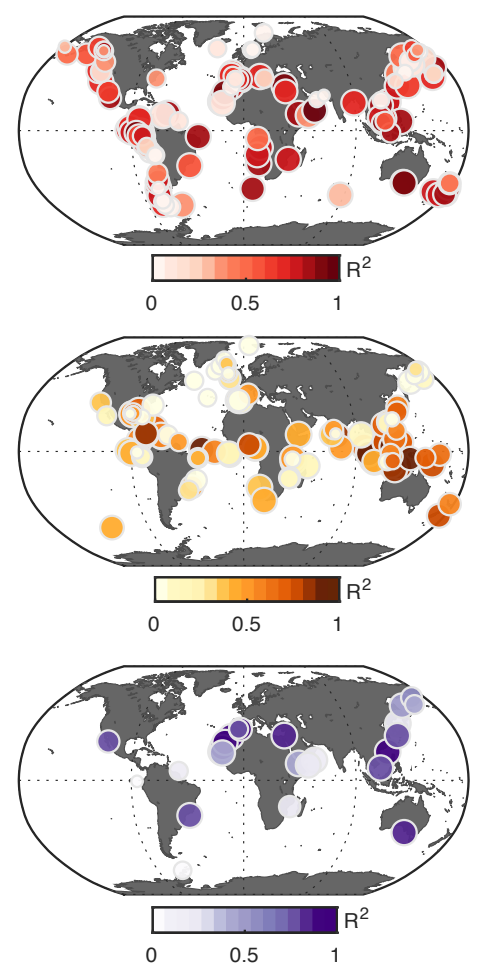

Extended Data Figure 2. Statistical validation of randomly withheld marine geochemical proxies. (a) From left: observed vs. forward-modeled $\delta^{18} \mathrm{O}_{c}$ values for each site using the posterior data assimilation estimates. Shown at right are the associated median (based on $n=300$ ensemble members) $\mathrm{R}_{\text {validation }}^{2}$ scores, computed on a per-site basis. (b-d) As in (a), but for $U_{37}^{K^{\prime}}, \mathrm{Mg} / \mathrm{Ca}$, and $\mathrm{TEX}_{86}$, respectively. 

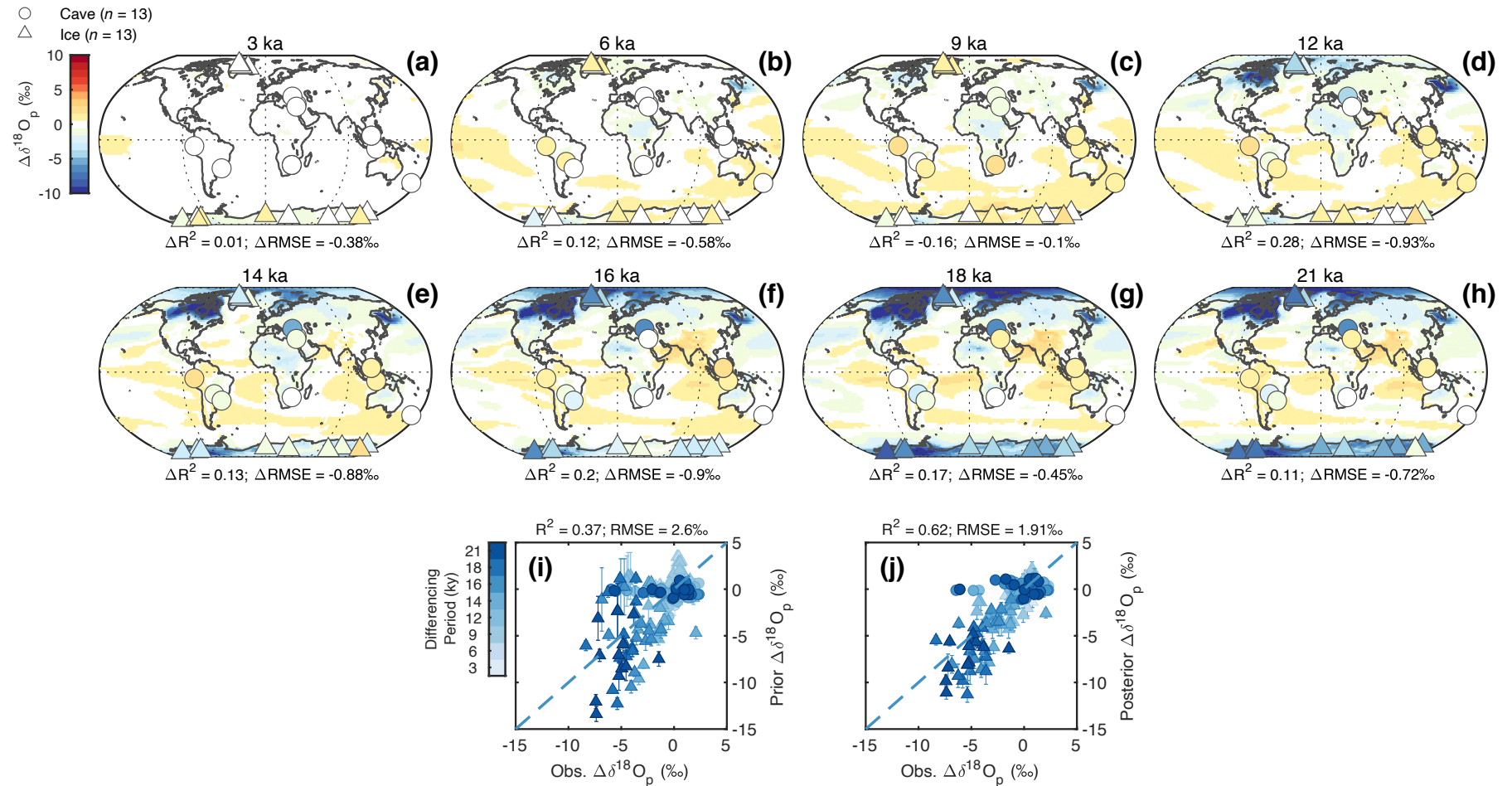

Extended Data Figure 3. Validation using independent $\delta^{18} \mathbf{O}_{p}$ ice core and speleothem records. (a) 3 ka - preindustrial (PI) posterior $\Delta \delta^{18} \mathrm{O}_{p}$ field; overlying dots show the observed $3 \mathrm{ka}-\mathrm{PI} \Delta \delta^{18} O_{p}$ values from speleothems and ice cores. Only records spanning at least 18 of the last $24 \mathrm{ka}$ are shown. $\Delta \mathrm{R}^{2}$ and $\triangle R M S E P$ values denote the change in observed vs. posterior assimilated $\Delta \delta^{18} O_{p}$ values relative to the prior (i.e., iCESM) estimated values. (b-h) As in (a), but for values differenced at 6, 9, 12, 14, 16, 18, and 21 ka vs. the PI, respectively. (i) All observed $\Delta \delta^{18} O_{p}$ vs. model prior values; dashed line indicates the 1:1 relationship. (j) All observed $\Delta \delta^{18} O_{p}$ vs. posteriors (a-h), which shows a strong improvement in $\Delta \mathrm{R}^{2}$ and $\triangle R M S E P$ over the prior. 


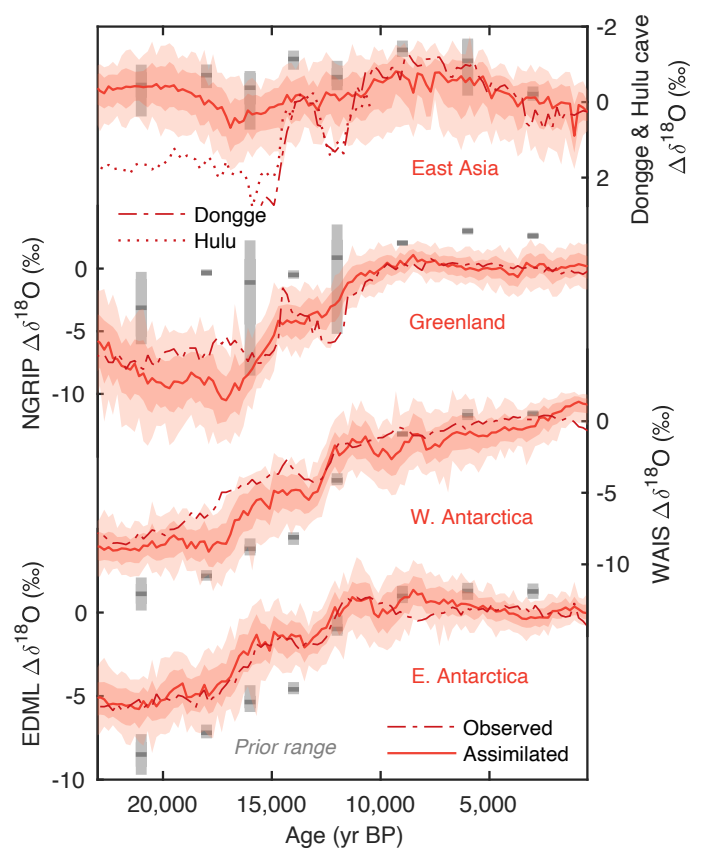

Extended Data Figure 4. Time-comparison of posterior LGMR with $\delta^{18} O_{p}$ with selected $\delta^{18} O_{p}$ ice core and speleothem records. Uncertainty ranges denote the $\pm 1 \sigma$ level (dark) and $95 \%$ confidence range from the LGMR ensemble. Also shown for comparison are the full range (shaded grey) and median iCESM time slice prior values (50 year means) for each site. See also Extended Data Table 2. 

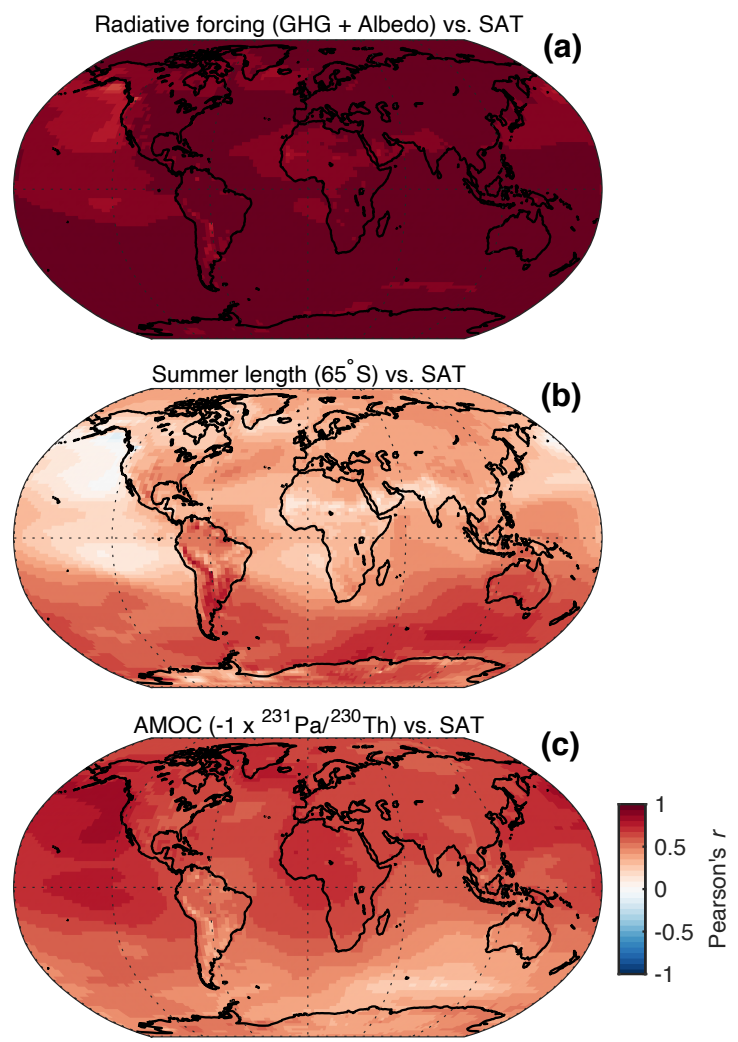

Extended Data Figure 5. Influences on global surface temperature evolution during the last 24 ka. Spatial LGM-to-present correlations between SAT and (a) combined greenhouse gas ${ }^{26}$ and global albedo radiative forcing ${ }^{28}$; (b) summer length at $65^{\circ} \mathrm{S}^{31}$; and (c) the $-1 \times{ }^{231} \mathrm{~Pa} /{ }^{230} \mathrm{Th}$ AMOC proxy index from Bermuda Rise ${ }^{33-35}$ (shown such that SAT correlations are positive with AMOC strength). 

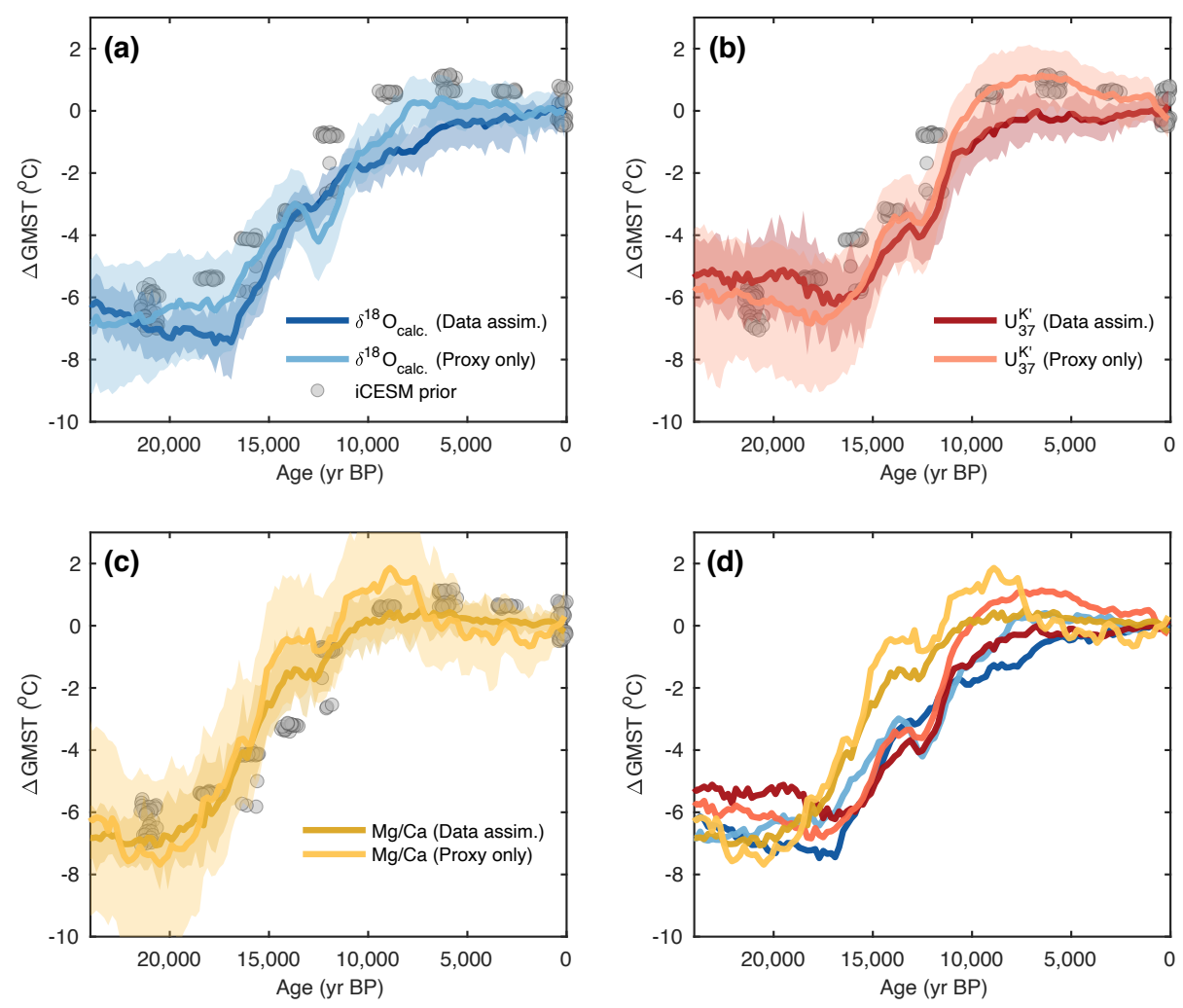

Extended Data Figure 6. Proxy-specific GMST reconstructions. $\delta^{18} \mathrm{O}_{\text {calc }}$ (a), $U_{37}^{K^{\prime}}$ (b), and $\mathrm{Mg} / \mathrm{Ca}$ (c). In (a-c), the shaded regions show the 95\% confidence range across $n=50$ ensemble members for the data assimilation derived GMST estimates, and $n=10,000$ realizations for the proxy-only GMST estimates. All GMST curves from (a-c) are shown in (d) for side-by-side visualization. 


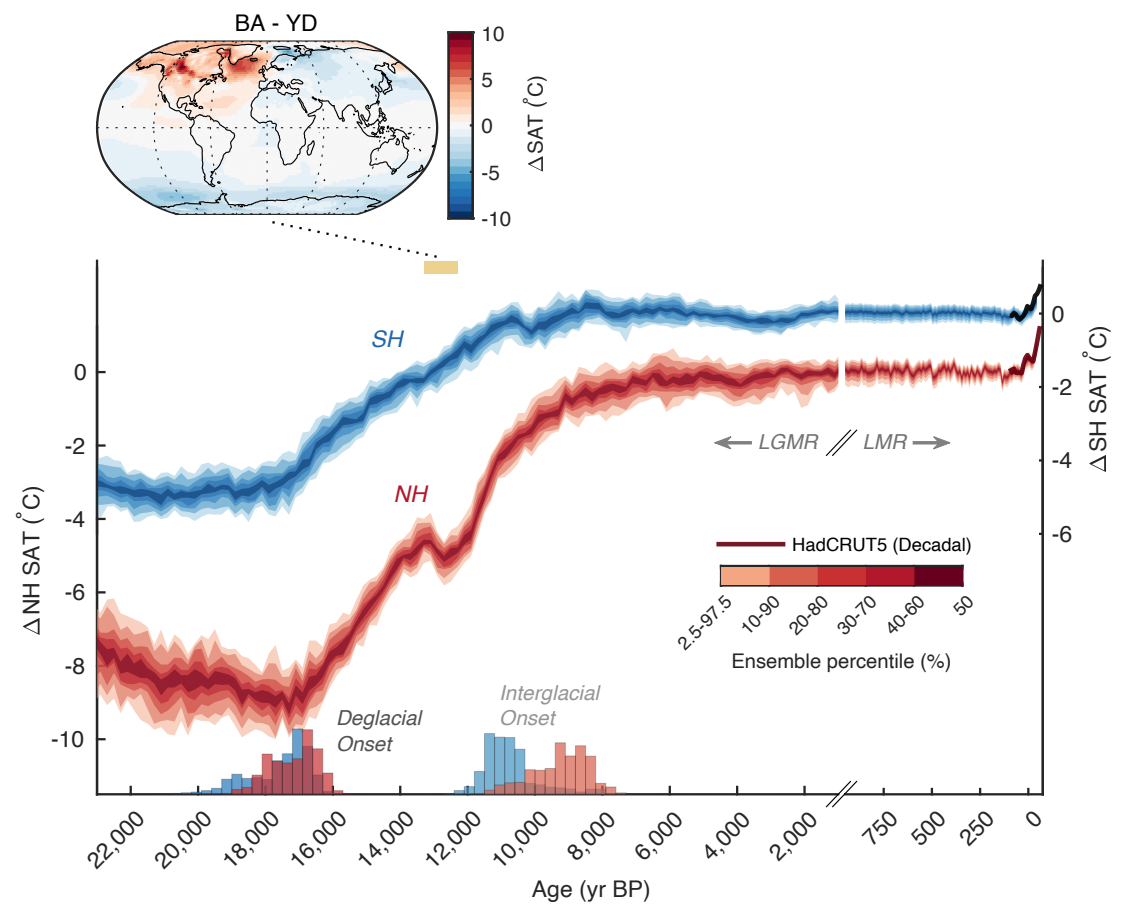

Extended Data Figure 7. Hemispheric variability during the last 24 ka. Ensemble distribution ( $n=$ 300) of LGMR-estimated Northern Hemisphere ( $\mathrm{NH}$; red, adjusted by $+2^{\circ} \mathrm{C}$ for improved visualization) and Southern Hemisphere ( $\mathrm{SH}$; grey) mean hemispheric temperatures during the last $24 \mathrm{ka}$. Shown at top is the surface temperature spatial difference for the Bølling-Allerød and Younger Dryas interval. Hemispheric last deglacial and interglacial onset timings are shown as histograms at bottom. The LGMR is plotted alongside reconstructed decadal hemispheric temperatures from the Last Millennium Reanalysis v2.1 ${ }^{18}$ and HadCRUT5 observational product ${ }^{11}$. 


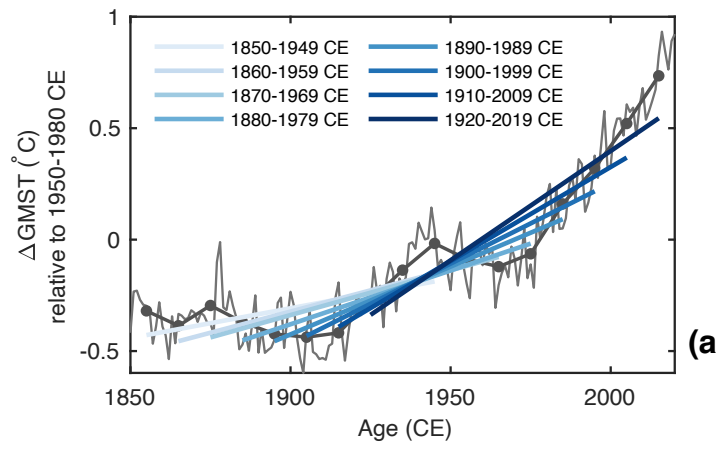

(a)
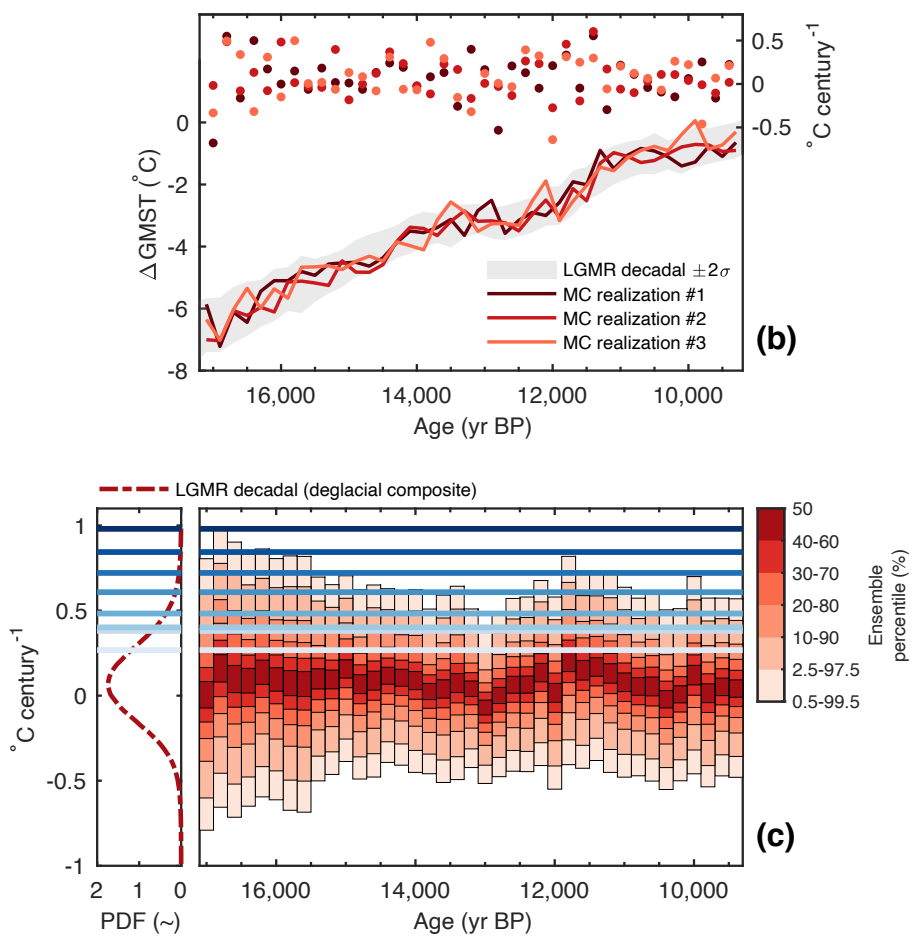

Extended Data Figure 8. Comparison between rates of warming in the LGMR and the recent historical record. (a) Observed centennial warming rates stepped decade-wise to present from HadCRUT5 11. (b) Example showing range of expected centennial-scale rates of deglacial warming (red scatter points) from three different Monte Carlo (MC)-based realizations of GMST change from the LGMR (red lines). Gray shading shows the decadal-adjusted LGMR $\pm 2 \sigma$ range. (c) Comparison of observed (HadCRUT5) warming rates from (a) (horizontal blue lines) to the distribution of warming rates from the decadal-adjusted LGMR ensemble. Observed centennial warming rates after $1900 \mathrm{CE}$ exceed the $99.9^{\text {th }}$ percentile of LGMR deglacial warming. 
Extended Data Table 1. Information on the iCESM simulations used for generating model priors. Greenhouse gas concentrations are in ppm for $\mathrm{CO}_{2}$ and ppb for $\mathrm{CH}_{4}$ and $\mathrm{N}_{2} \mathrm{O}$. Global mean seawater $\delta^{18} \mathrm{O}$ $\left(\delta^{18} \mathrm{O}_{s w}\right)$ is in \% relative to the Vienna Standard Mean Ocean Water (VSMOW). See Methods for details of the implementation of vegetation and freshwater forcing in related simulations.

\begin{tabular}{|c|c|c|c|c|c|}
\hline $\begin{array}{l}\text { Age } \\
(\mathbf{k a})\end{array}$ & $\begin{array}{c}\text { Model } \\
\text { description }\end{array}$ & $\begin{array}{l}\text { Number } \\
\text { of priors }\end{array}$ & $\begin{array}{l}\text { Greenhouse gas } \\
\left(\mathrm{CO}_{2} / \mathrm{CH}_{4} / \mathrm{N}_{2} \mathrm{O}\right)\end{array}$ & $\begin{array}{l}\text { Global } \\
\delta^{18} \mathbf{O}_{\text {sw }}\end{array}$ & Citation \\
\hline 0 & iCESM1.2: PI & 16 & $285 / 792 / 276$ & 0.05 & 10 \\
\hline 0 & iCESM1.2: PI & 10 & 285 / 792 / 276 & 0.05 & 56 \\
\hline 0 & iCESM1.3: PI & 10 & $285 / 792 / 276$ & 0.05 & 56 \\
\hline 0 & iCESM1.2 Last Millennium & 20 & Transient & 0.05 & 57 \\
\hline 0 & $\begin{array}{l}\text { Memeber \#2: 850-1850 CE } \\
\text { iCESM1.2 Last Millennium } \\
\text { Member \#3: 850-1850 CE }\end{array}$ & 20 & Transient & 0.05 & 57 \\
\hline 3 & iCESM1.2: $3 \mathrm{ka}$ & 16 & $275 / 580 / 270$ & 0.05 & 10 \\
\hline 6 & $\begin{array}{c}\text { iCESM1.2: } 6 \mathrm{ka} \mathrm{w} / \\
\text { Sahara \& 50-90 } \mathrm{N} \text { greened }\end{array}$ & 16 & 264 / 597 / 262 & 0.05 & This study \\
\hline 6 & iCESM1.2: $6 \mathrm{ka}$ & 8 & 264 / 597 / 262 & 0.05 & This study \\
\hline 9 & $\begin{array}{l}\text { iCESM1.2: } 9 \mathrm{ka} \mathrm{w} / \\
\text { Sahara greened }\end{array}$ & 16 & $260 / 659 / 255$ & 0.34 & This study \\
\hline 12 & iCESM1.2: $12 \mathrm{ka}$ & 16 & 253 / 478 / 236 & 0.59 & This study \\
\hline 12 & $\begin{array}{l}\text { iCESM1.2: } 12 \mathrm{ka} \mathrm{w/} \\
\text { freshwater over N. Atl. }\end{array}$ & 4 & $253 / 478 / 236$ & 0.59 & This study \\
\hline 14 & iCESM1.2: $14 \mathrm{ka}$ & 16 & $238 / 637 / 255$ & 0.73 & This study \\
\hline 16 & iCESM1.2: $16 \mathrm{ka}$ & 16 & 224 / 452 / 199 & 0.90 & This study \\
\hline 16 & $\begin{array}{l}\text { iCESM1.2: } 16 \mathrm{ka} \mathrm{w/} \\
\text { freshwater over N. Atl. }\end{array}$ & 4 & 224 / 452 / 199 & 0.90 & This study \\
\hline 18 & iCESM1.2: $18 \mathrm{ka}$ & 16 & $190 / 370 / 245$ & 1.02 & 10 \\
\hline 21 & iCESM1.2: $21 \mathrm{ka}$ & 16 & $190 / 375 / 200$ & 1.05 & 10 \\
\hline 21 & iCESM1.3: $21 \mathrm{ka}$ & 18 & $190 / 375 / 200$ & 1.05 & 56 \\
\hline
\end{tabular}


Extended Data Table 2. Geographical and site identification information for ice core and speleothem $\delta^{18} \mathbf{O}_{p}$ records used for LGMR external validation.

\begin{tabular}{ccccccc} 
Proxy class & Site name & Lat. $\left({ }^{\circ} \mathbf{N}\right)$ & Lon. $\left({ }^{\circ} \mathbf{E}\right)$ & $\mathbf{R}^{2}$ & $\mathbf{C E}$ & Citation \\
\hline Ice core & Byrd & -80.02 & -119.53 & 0.82 & -0.71 & 72 \\
Ice core & EDC & -75.10 & 123.35 & 0.89 & 0.49 & 73 \\
Ice core & EDML & -75.00 & 0.07 & 0.86 & 0.78 & 73 \\
Ice core & Fuji & -77.32 & 38.70 & 0.83 & 0.66 & 74 \\
Ice core & Siple & -81.65 & -149.00 & 0.88 & 0.64 & 75 \\
Ice core & TALDICE & -72.82 & 159.18 & 0.89 & 0.76 & 76 \\
Ice core & Taylor & -77.78 & 158.72 & 0.65 & -0.65 & 77 \\
Ice core & Vostok & -78.46 & 106.84 & 0.88 & 0.85 & 78 \\
Ice core & WAIS & -79.47 & -112.00 & 0.87 & 0.22 & 79 \\
Ice core & Renland & 71.27 & -26.73 & 0.74 & 0.20 & 80 \\
Ice core & GISP2 & 72.60 & -38.50 & 0.65 & 0.05 & 81 \\
Ice core & GRIP & 72.58 & -37.63 & 0.58 & -0.21 & 82 \\
Ice core & NGRIP & 75.10 & -42.33 & 0.71 & 0.55 & 83 \\
Speleothem & Cold Air cave & -24.00 & 29.18 & 0.08 & -14.58 & 84 \\
Speleothem & Jaraguá cave & -21.08 & -56.58 & 0.27 & -1.63 & 85 \\
Speleothem & Jeita cave & 33.95 & 35.65 & 0.01 & -15.69 & 86 \\
Speleothem & Mawmluh cave & 25.26 & 91.88 & 0.42 & -4.47 & 87 \\
Speleothem & Liang Luar cave & -8.53 & 120.43 & 0.06 & -5.19 & 88 \\
Speleothem & Bukit Assam cave & 4.03 & 114.80 & 0.04 & -5.23 & 89 \\
Speleothem & Xiaobailong cave & 24.20 & 103.36 & 0.20 & -3.55 & 90 \\
Speleothem & Sofular cave & 41.42 & 31.93 & 0.04 & -1.86 & 91 \\
Speleothem & Botuverá & -27.22 & -49.16 & 0.10 & -7.88 & 92 \\
Speleothem & Gunung-buda cave & 4.03 & 114.80 & 0.02 & -2.66 & 89 \\
Speleothem & Nettlebed cave & -41.25 & 172.63 & 0.27 & -4.11 & 93 \\
Speleothem & Soreq cave & 31.76 & 35.02 & 0.17 & -5.45 & 94 \\
Speleothem & El Condor cave & -5.93 & -77.30 & 0.02 & -0.42 & 95 \\
\hline & & & & & &
\end{tabular}


Extended Data Table 3. External validation statistics associated with different choices of covariance localization and the $1 \sigma$ "length-scale" range of the evolving prior sampling. $\triangle \mathrm{R}^{2}$ and $\triangle R M S E P$ values denote the change in observed vs. posterior assimilated $\Delta \delta^{18} O_{p}$ values relative to the prior iCESM estimated values; larger $\Delta \mathrm{R}^{2}$ and smaller $\triangle R M S E P$ thus denote greater improvement in the assimilated posterior relative to iCESM (see Extended Data Figure 2i-j for plotted LGMR values). For localization testing, listed $\Delta \mathrm{R}^{2}$ and $\triangle R M S E P$ values represent the median across all $(n=6)$ length-scale tests; for length-scale testing, listed $\Delta \mathrm{R}^{2}$ and $\triangle R M S E P$ values represent the median across all $(n=8)$ localization tests.

\begin{tabular}{ccccccccc} 
Localization $(\mathbf{k m}):$ & $\mathbf{6 , 0 0 0}$ & $\mathbf{9 , 0 0 0}$ & $\mathbf{1 2 , 0 0 0}$ & $\mathbf{1 5 , 0 0 0}$ & $\mathbf{1 8 , 0 0 0}$ & $\mathbf{2 1 , 0 0 0}$ & $\mathbf{2 4 , 0 0 0}$ & $\infty$ \\
\hline$\Delta R^{2}$ & 0.09 & 0.19 & 0.23 & 0.24 & 0.24 & 0.25 & 0.25 & 0.16 \\
$\Delta R M S E P(\% \mathbf{0})$ & -0.54 & -0.59 & -0.63 & -0.63 & -0.64 & -0.72 & -0.73 & -0.34 \\
Length scale (yr) : & $\mathbf{2 , 0 0 0}$ & $\mathbf{3 , 0 0 0}$ & $\mathbf{4 , 0 0 0}$ & $\mathbf{5 , 0 0 0}$ & $\mathbf{6 , 0 0 0}$ & $\infty$ & & \\
\hline$\Delta R^{2}$ & 0.23 & 0.24 & 0.25 & 0.24 & 0.23 & 0.18 & & \\
$\Delta R M S E P\left(\mathbf{\% 0}_{0}\right)$ & -0.63 & -0.62 & -0.64 & -0.65 & -0.69 & -0.58 & & \\
\hline
\end{tabular}

